\title{
Structural Analysis and Improvement Design of Brake Pressure Valve Feedback Stage in Multivalve Parallel Brake System
}

\author{
Zhi-peng Huang, ${ }^{1}$ Bin Yu $\mathbb{D}^{1},{ }^{1}$ Yun-he Wang, ${ }^{1}$ Qi-wei Zhang, ${ }^{2}$ Yan Xie, ${ }^{3}$ Zuo-jian Xie, \\ and Xiang-dong Kong ${ }^{1}$ \\ ${ }^{1}$ School of Mechanical Engineering, Yanshan University, Qinhuangdao 066004, China \\ ${ }^{2}$ Beijing Automation Control Equipment Institute, Beijing 100074, China \\ ${ }^{3}$ The First Aircraft Institute, Xian 710089, China \\ ${ }^{4}$ Shanghai Hengtuo Hydraulic Control Technology Co., Ltd., Shanghai 200031, China
}

Correspondence should be addressed to Bin Yu; yb@ysu.edu.cn

Received 29 June 2021; Revised 24 September 2021; Accepted 6 October 2021; Published 20 October 2021

Academic Editor: Francisco Beltran-Carbajal

Copyright () 2021 Zhi-peng Huang et al. This is an open access article distributed under the Creative Commons Attribution License, which permits unrestricted use, distribution, and reproduction in any medium, provided the original work is properly cited.

\begin{abstract}
The wheel brake device is one of the most widely used landing deceleration devices in modern aircraft. For large aircraft, a multivalve parallel brake system is usually used. When a brake pressure servo valve of a certain type of aircraft is debugged, the output brake pressure of the system shows obvious periodic oscillation with constant amplitude. This paper focuses on the brake pressure servo valve, which is the key component of the system. There are a large number of feedback and adjustment segments in the brake pressure servo valve, which can not only improve the control accuracy but also introduce nonlinear factors to cause system vibration. Therefore, in this paper, the feedback stage structure of the brake pressure servo valve is analyzed and improved, and a new two-stage pressure servo valve is designed to restrain the output brake pressure vibration of the system. Firstly, the structure principle of the original pressure servo valve is defined, and the function of the feedback stage is analyzed. Secondly, in view of the vibration problem caused by the original brake pressure servo valve, a new two-stage brake pressure servo valve is designed, which is the main contribution of this paper. Thirdly, the dynamics model of the proposed two-stage brake pressure servo valve is established, and the simulation model of the brake pressure servo valve-controlled cylinder system and the multivalve parallel brake servo control system is built. Finally, experiments are carried out on the experimental platform of a multivalve parallel brake system to verify that the proposed two-stage pressure servo valve can restrain the vibration of the system more effectively than the original brake pressure servo valve. And the two-stage pressure servo valve prototype is successfully applied to the actual aircraft brake control system; the system can better maintain a stable brake pressure output.
\end{abstract}

\section{Introduction}

Large aircraft is one of the important signs to measure the comprehensive national strength of a country. It is not only related to the national economy but also of great significance to the maintenance of national security and national interests $[1,2]$. In the flight control system of large aircraft, the brake system is important airborne equipment of the aircraft, which has an important influence on the safety of takeoff and landing [3-5]. The brake system not only ensures that the plane's taxiing direction on the ground is controllable but also ensures that the plane lands in the shortest distance and brakes safely under the condition of aborting take-off. To meet the take-off and landing requirements of large aircraft, the main landing gear with multiple wheels in parallel is mostly used in the braking system of large aircraft [6-8]. When multiple sets of wheel brake devices are used in parallel, problems such as strong nonlinear system, timevarying parameters, and complex random load will be magnified in geometric multiples, which can easily lead to vibration instability of large aircraft wheel brake system, increasing the control difficulty and reducing the reliability 
of the system $[9,10]$. If the vibration occurs in the test flight system, it is very likely to cause flight accidents, resulting in serious consequences that cannot be predicted. Therefore, it is necessary to carry out detailed research on the vibration characteristics, vibration influencing factors, and vibration suppression methods of the electrohydraulic braking servo control system of multiwheel parallel brake system for large aircraft.

Kang et al. [11] used transient numerical simulation to analyze the pressure pulsation and hydrodynamic oscillation trend of the servo valve pilot stage flow field and studied the influence of the servo valve pilot stage flow force on the pressure stability of the control chamber by fitting the numerical simulation data of the flow force with different baffle displacements. Jiao et al. [12] proposed a new type of fly-by-wire aircraft power braking system (PWABS), which only consumes the electric power from the aircraft to realize the braking function, rather than through the hydraulic system. At the same time, it replaces the servo valve with the on-off valve to suppress the vibration of the aircraft when braking without the use of the hydraulic system. Aravind et al. [13] proposed an improved braking controller position control model, which modified the control mode by using empirical mapping knowledge to reduce the vibration of the braking system. Sinou et al. [14] proposed and established a nonlinear analysis model of modal aircraft braking rotation and determined the influence of system parameters on system stability by using the linear stability theory. Yin et al. [15] effectively suppressed the vibration of the aircraft brake system by adding a damping layer in the brake mechanism and the damping stator edge chamfering design. The above research has enriched the research on the vibration influencing factors and vibration suppression of the aircraft brake control system, but there is little analysis on whether the structural principle of the servo valve causes pressure oscillation on the brake system. Therefore, it is necessary to analyze the influence of the internal structure of the servo valve on the vibration of the braking system.

The frequency bandwidth of the three-stage electrohydraulic servo valve can meet the requirements of highperformance equipment [16]. The three-stage electrohydraulic servo valve can use several milliamps of the electrical signal to control the output of large hydraulic power, drive load, and achieve high-performance movement, but it also has the advantages of strong antipollution ability, long service life, and high reliability [17]. However, cavitation is easy to occur in the pilot stage flow field of the three-stage electrohydraulic servo valve, and damage to the baffle, feedback spring, and nozzle of the servo valve is easy to occur [18]. Wang and Yin [19] analyzed the reliability and sensitivity of the servo valve and found that the three-stage electrohydraulic servo valve has a large number of nonlinear links and often produces random vibration in the process of use. Tetsuya et al. [20] improved the dynamic characteristics of the servo valve by modifying the internal controller of the servo motor. Wang et al. [21] analyzed the valve spool and valve sleeve. Through improving the matching accuracy of the two, leakage of servo valve was reduced and reliability was improved. Lv et al. [22] analyzed the nozzle flapper valve, and a new performance parameter of pressure-sensitivity coefficient number is proposed to reflect the character of pressure variation in the deflector pilot stage, which changed the configuration of the inlet nozzle and improved the performance of the pilot stage of the diversion plate. The above researches enrich the methods of improving the performance of the servo valve by changing the structure of the servo valve, but there are few researches on improving the performance of the servo valve by changing the feedback stage structure of the servo valve. Therefore, this paper analyzes and improves the internal feedback stage structure of the pressure valve in a multivalve parallel brake system. A new two-stage pressure servo valve was designed to suppress the vibration caused by the unreasonable internal structure.

The research work in this paper mainly includes principle analysis of brake pressure servo valve, design of new brake pressure servo valve, dynamics simulation analysis, and multivalve parallel experiment verification. The innovative achievements are as follows:

(1) The working principle of the brake pressure servo valve is analyzed in detail, and the feedback stage function of the brake pressure servo valve is analyzed. It is determined that the internal pressure feedback mechanism of the valve body affects the stability of the brake output pressure.

(2) A two-stage brake pressure servo valve is proposed, the precise dynamics model of the brake pressure servo valve is established, and the simulation models of the brake pressure servo valve-controlled cylinder system and the multivalve parallel brake servocontrolled system are built. The experiments verify that the improved brake pressure servo valve could effectively suppress the vibration of the system.

The content of each section is arranged as follows. Section 1 introduces the working principle of the original brake pressure servo valve and analyzes its feedback stage action. In Section 2, the dynamic model of the new two-stage brake pressure servo valve and the simulation model of the brake pressure servo valve-controlled cylinder system are established. In Section 3, the simulation model of the multivalve parallel brake servo control system is built and analyzed, and the vibration of the new brake pressure servo valve is theoretically analyzed. In Section 4, the experimental platform of the multivalve parallel braking system is built, and the simulation results are compared and verified in the experimental platform.

\section{Analysis of Original Brake Pressure Servo Valve}

2.1. Introduction of Working Principle. A brake pressure servo valve is a kind of jet pipe pressure servo valve. Figure 1 shows the structure of the brake pressure servo valve. The brake pressure servo valve is a three-stage electrohydraulic servo valve with output brake pressure control realized by pressure feedback. In Figure 1, port P is the high-pressure oil inlet, which is connected with the hydraulic oil source. High- 


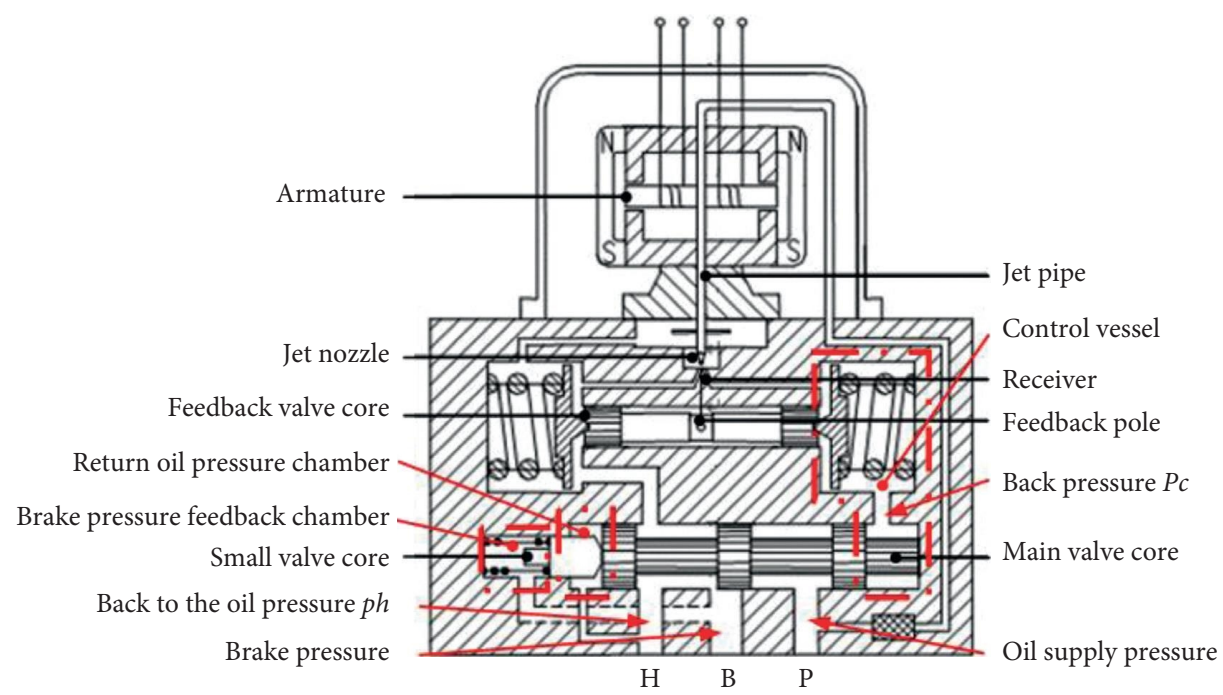

Figure 1: Brake pressure servo valve structure.

pressure oil entering through port $\mathrm{P}$ reaches the jet pipe through the filter element and the oil circuit on the right side of the valve body and finally forms a high-speed jet at the jet nozzle. Port B is the working port, connected with the brake actuator, and communicated with the brake pressure feedback chamber on the left side of the small valve core. Port $\mathrm{H}$ is the oil return port, connected with the oil return channel, and communicated with the oil return pressure chamber on the left side of the main valve core of the power stage. Under the joint action of negative feedback of brake pressure and negative feedback of torque of jet tube-feedback lever assembly, the brake pressure servo valve will output relatively stable brake pressure.

The main characteristic of the brake pressure servo valve is its unique unilateral control mode, which is different from other brake pressure servo valves. The front stage of this type of brake pressure servo valve is the unilateral control structure of the right receiving hole. The jet tube receiver assembly is biased during assembly; that is, the jet nozzle is biased to the left receiving hole of the receiver. When the torque motor does not receive the current signal, the flow of the jet nozzle flows back to the tank through the left receiving hole of the receiver. When the torque motor receives the current signal, the jet nozzle deflects to the right under the action of the armature component and continuously coincidences with the receiver's right receiving hole, so that the pressure oil enters the control chamber to form the control pressure. The power stage of the brake pressure servo valve is a unilateral control structure. Only the right end of the power stage valve core is controlled by the control pressure, and only the right side of the middle shoulder of the power stage main valve core of the brake pressure servo valve participates in the control of the brake pressure when working.

2.2. Function Analysis of Feedback Stage of Brake Pressure Servo Valve. According to the working principle of the brake pressure servo valve, it can be seen that, in the working process, the function of the feedback stage is that in the process of establishing the recovery pressure $p_{c}$, the negative feedback to the torque motor is formed by the feedback rod to improve the stability and control precision of the recovery pressure $p_{c}$. At the same time, under the combined action of the negative feedback of the feedback rod and the oil impedance of the control chamber, the recovery pressure pc will not generate too much overshot $p_{b}$, which further improves the stability of the system. The front stage of the brake pressure servo valve adopts a unique unilateral control mode, and $p_{c}$ is not affected by the feedback effect of the brake pressure output by the system. If the negative feedback effect of the feedback lever is not introduced, $p_{c}$ will become an uncontrolled quantity, thus causing the inaccurate output of the brake pressure of the system.

Combined with the above analysis, the theoretical function of setting the feedback stage of the brake pressure servo valve is to improve the stability and control precision of the system. However, during the debugging of the brake pressure servo valve of a certain type of aircraft, it is found that the brake pressure output by the system still has an obvious constant amplitude periodic oscillation phenomenon, as shown in Figure 2. Therefore, it remains to be further analyzed whether the feedback stage of the brake pressure servo valve plays a role in improving the stability of the system in actual work.

\subsubsection{Analysis of the Actual Function of Feedback Stage.} Based on the principle and structure of the original brake pressure servo valve, the structure of the brake pressure servo valve-controlled cylinder system is built, as shown in Figure 3.

When the oil supply pressure is $p_{s}=15 \mathrm{MPa}$ and the step current signal of torque motor is $40 \mathrm{~mA}$, the brake pressure output by the brake pressure servo valve is shown in Figure 4. Under the action of the step current signal, the brake pressure forms a stable constant amplitude oscillation phenomenon, and its peak-to-peak 


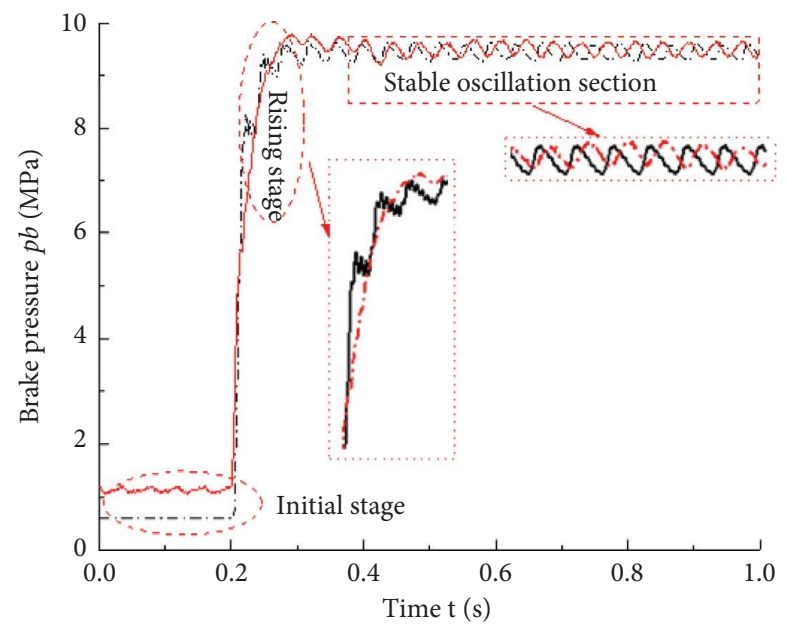

Figure 2: The experimental results of servo valve pressure output.

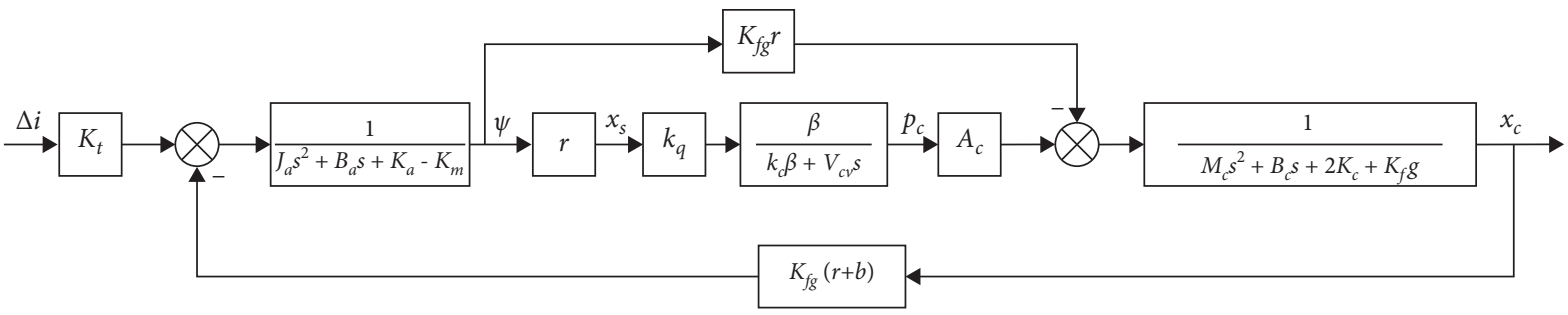

(a)

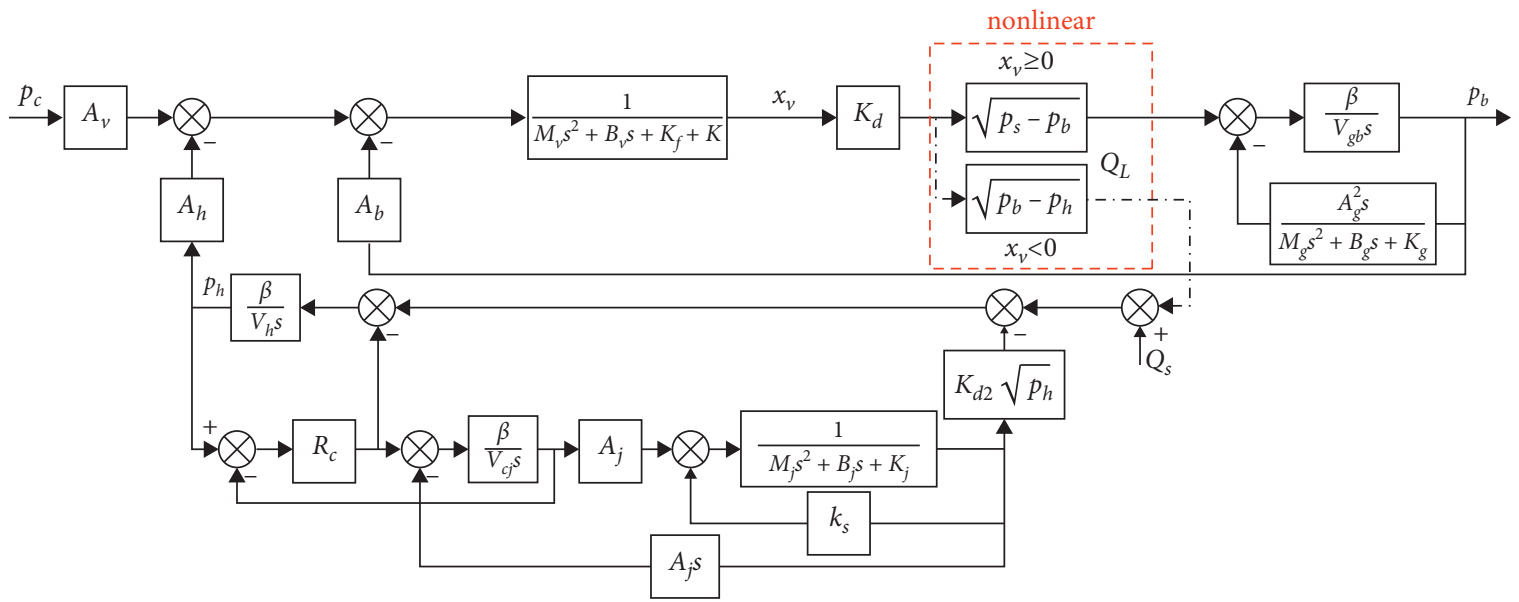

(b)

Figure 3: The structure of brake pressure servo valve-controlled cylinder. (a) The control structure of brake pressure servo valve pilot stage. (b) The control structure of brake pressure servo valve power stage.

value is about $0.40 \mathrm{MPa}$. In order to analyze the specific characteristics of the stable oscillation section, FFT analysis is performed on the curve of the stable oscillation section. During FFT analysis, the sampling frequency is usually more than twice the system frequency, which is estimated to be $15 \mathrm{~Hz}$ by simulation. Therefore, the sampling frequency of $60 \mathrm{~Hz}$ is selected for FFT analysis within the range of $0-100 \mathrm{~Hz}$ where the oscillation is obvious, and the FFT spectrum of the stable oscillation brake pressure was obtained in Figure 5(b). The main frequency of constant amplitude oscillation of the brake pressure was about $25 \mathrm{~Hz}$.

As the inducing factor of brake pressure oscillation, the oil return pressure $p_{h}$ also oscillates in constant amplitude, as shown in Figure 4. It can be found that, in the experimental test and simulation analysis, the main frequency of oil return pressure oscillation is about $25 \mathrm{~Hz}$, which is consistent with the main frequency of brake pressure oscillation.

Combined with Figure 1, it can be found that the oil return channel of the brake pressure servo valve is connected 


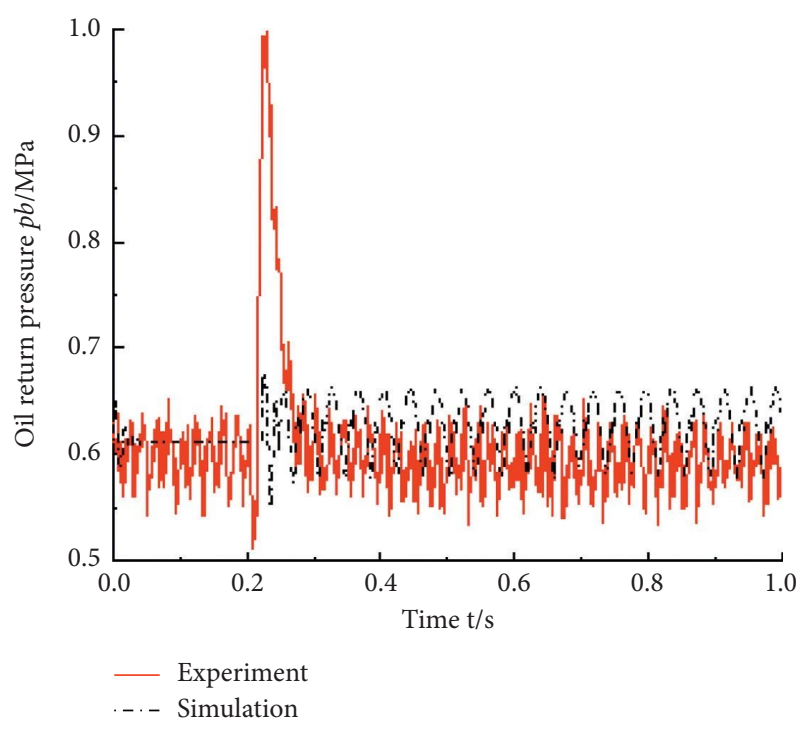

(a)

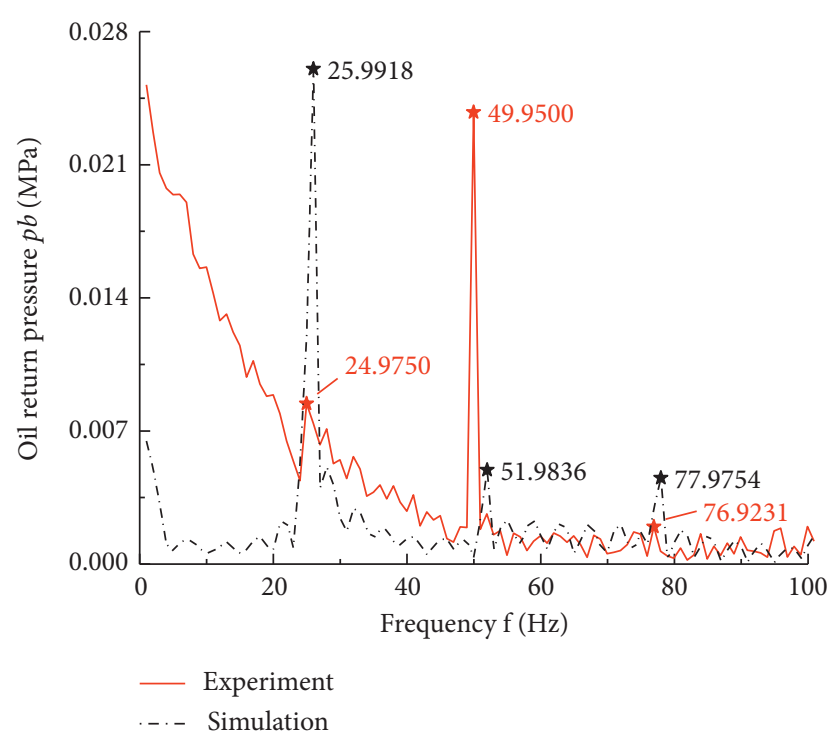

(b)

FIgURE 4: Simulation results of oil return pressure $p_{h}$. (a) Time domain. (b) Frequency domain.

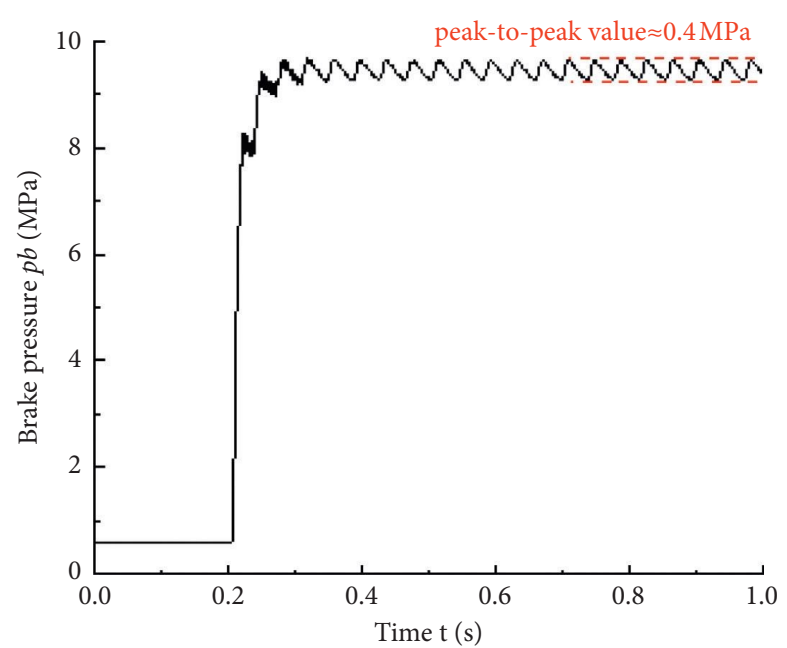

(a)

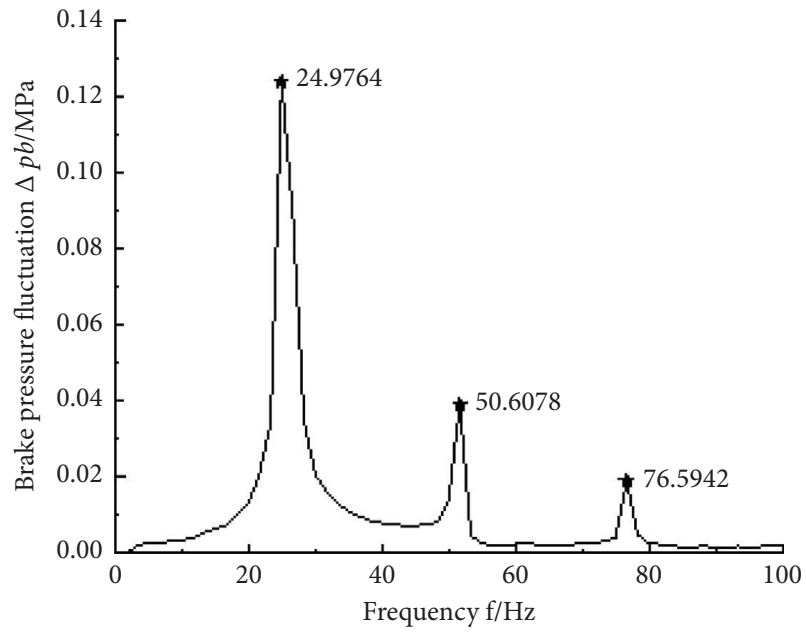

(b)

FIGURE 5: The brake pressure under step signal. (a) Brake pressure time domain curve. (b) Brake pressure frequency domain curve.

with the left chamber of the feedback stage valve core, and the left chamber of the feedback stage valve core is also connected with the outlet chamber of the jet pipe. Therefore, when the return oil pressure $p_{h}$ has constant amplitude oscillation, it not only generates a feedback effect on the power stage valve core through the internal flow channel but also influences the feedback stage and even the jet amplifier through the oil return channel in the valve body.

Therefore, the outlet chamber pressure $p_{0}$ of the jet pipe and the valve core displacement $x_{c}$ of the feedback stage are calculated through the MATLAB/Simulink simulation model in Figure 3, as shown in Figure 6. The outlet chamber pressure $p_{0}$ of the jet pipe has obvious constant amplitude oscillation with a dominant frequency of $26.24 \mathrm{~Hz}$. The displacement $x_{c}$ of the feedback stage valve core also has an oscillation phenomenon, but due to the high stiffness of the feedback stage spring, its oscillation amplitude is about $2 \times 10^{-7} \mathrm{~m}$, which is almost negligible.

Under the action of cavity pressure $p_{0}$ at the outlet of the jet pipe and feedback stage valve core displacement $x_{c}$, the oscillation phenomenon as shown in Figure 7 also appears in the recovery pressure $p_{c}$. Figure 7 (a) shows the simulation analysis results. In order to facilitate observation, the curve of return oil pressure $p_{h}$ in Figure $7(\mathrm{~b})$ has been shifted. It can be seen that both peak-to-peak and dominant frequency of the oscillation of recovery pressure $p_{c}$ is very close to the oscillation of return oil pressure $p_{h}$. Figure $7(\mathrm{~b})$ is the experimental test result of a factory, from which a phenomenon similar to the simulation analysis result can be observed. 


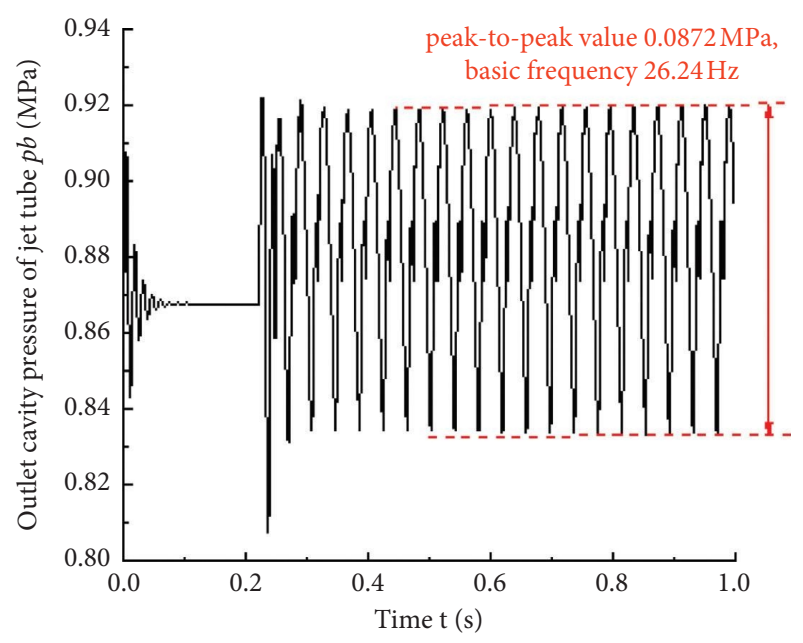

(a)

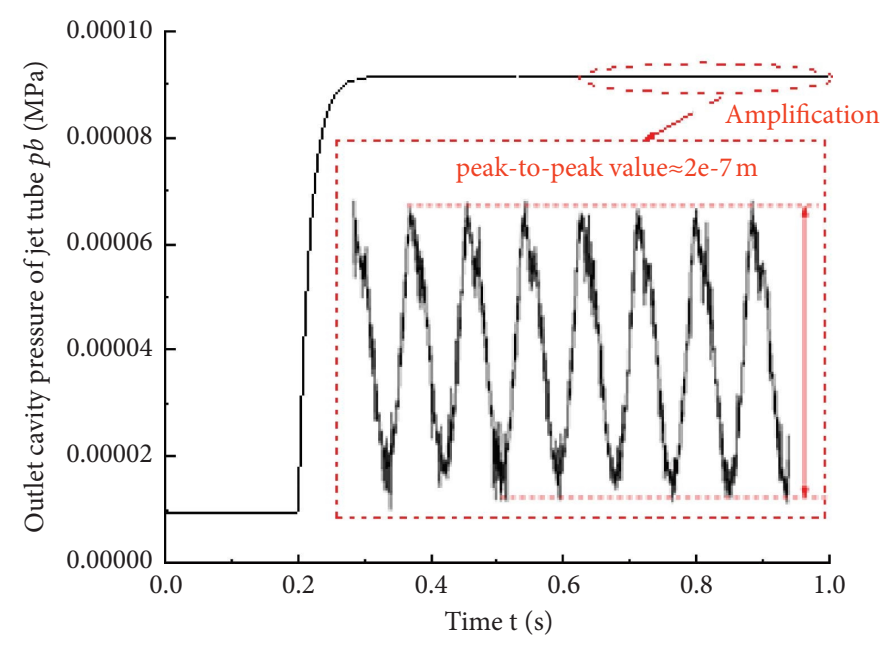

(b)

Figure 6: Matlab/Simulink simulation results. (a) Outlet chamber pressure of the jet pipe. (b) Feedback valve core displacement.

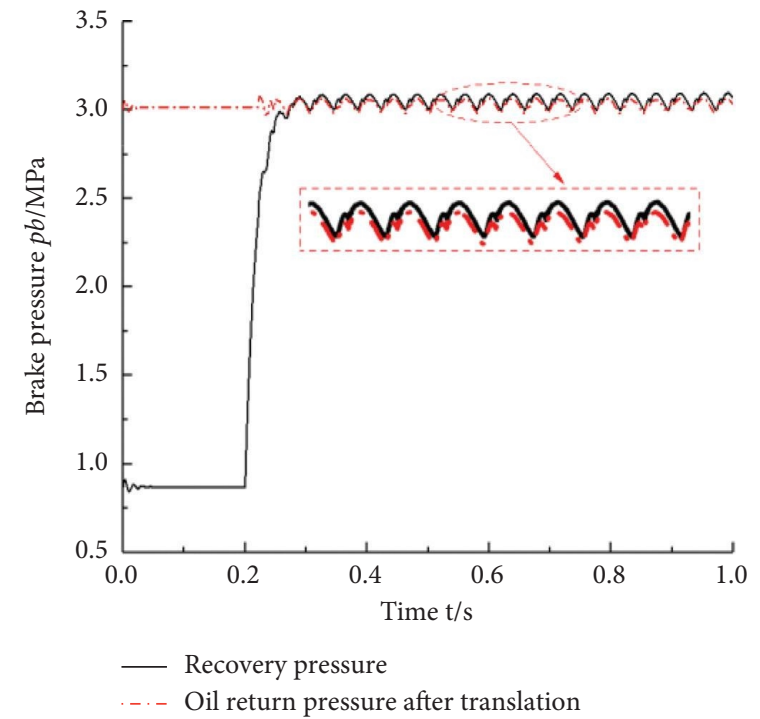

(a)

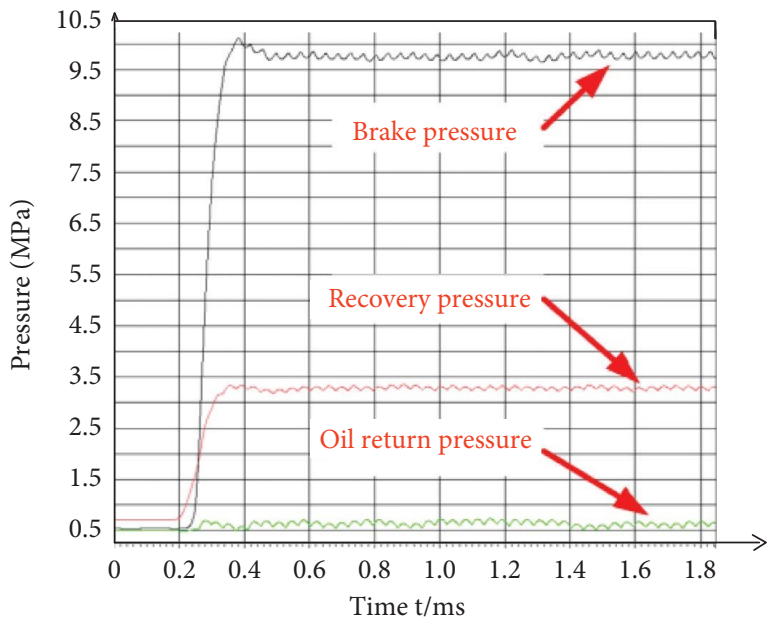

(b)

FiguRE 7: Recovery pressure $p_{c}$ for oscillation. (a) Simulation results. (b) Experimental test results.

By analyzing the establishment process of the force balance equation of the power stage valve core [20], the direction of the force exerted by the recovery pressure $p_{c}$ on the power stage valve core is just opposite to the return oil pressure $p_{h}$. Therefore, the feedback stage of the brake pressure servo valve can play the role of balancing the positive feedback of $p_{h}$ of the return oil pressure.

In the Matlab/Simulink model of the brake pressure servo valve-controlled cylinder system, the time-varying return oil pressure in the recovery pressure submodel and the feedback valve core displacement submodel was changed to the fixed return oil pressure of $0.6 \mathrm{MPa}$. In this case, the effect of return oil pressure on the feedback stage is cut off. Such a change will not affect the negative feedback effect of the feedback stage on the torque motor. Therefore, the feedback stage still plays a role in improving the stability and control precision of the recovery pressure $\mathrm{pc}$ in the process of establishing the recovery pressure.

At this point, the recovery pressure $p_{c}$ is obtained in Figure 8 . It can be seen that the recovery pressure $p_{c}$ rose rapidly and remained constant.

Meanwhile, brake pressure $p_{b}$ and return oil pressure $p_{h}$ were solved, as shown in Figure 9. It can be seen that after the influence of return oil pressure on the feedback stage is cut off, the brake pressure and return oil pressure will still produce a constant amplitude oscillation phenomenon, and compared with the $p_{h}$ dynamic feedback, there are the following differences: the oscillation amplitude increases 


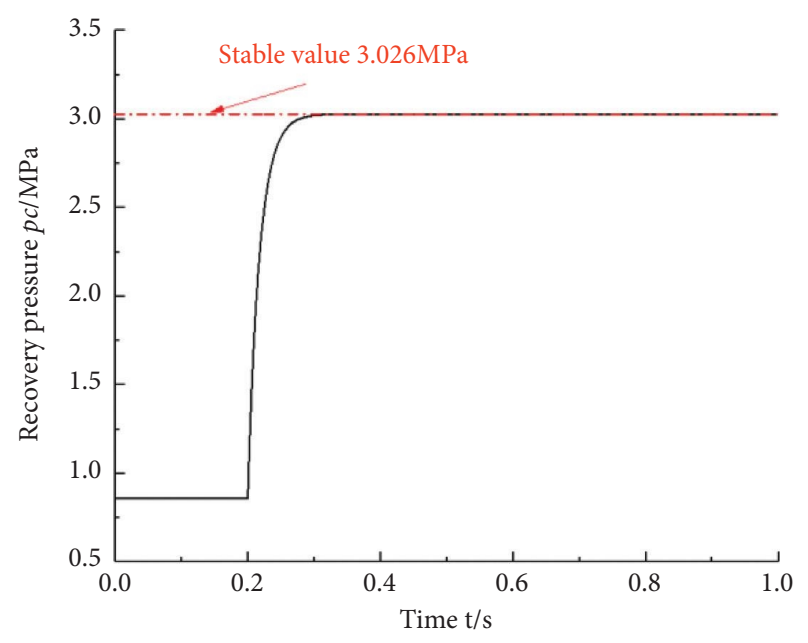

FIGURE 8: Simulation curve of the front stage under fixed return oil pressure.

obviously, in which the $p_{b}$ oscillation peak to peak of brake pressure increases by 28 times, and the $p_{h}$ oscillation peak to peak of return oil pressure increases by 65 times. The frequency characteristics of the oscillation of brake pressure $p_{b}$ and return oil pressure $p_{h}$ are completely consistent, while the frequency characteristics of brake pressure are closer to the recovery pressure $p_{c}$ under dynamic return oil pressure $p_{h}$. The comparative analysis results show that if considering the effect of dynamic oil return pressure on the feedback stage of the brake pressure servo valve, the oscillation of the system will be greatly suppressed.

The closed-loop feedback of brake pressure only acts on the power stage valve core and does not participate in the control process of restoring pressure $p_{c}$. If there is no negative feedback effect of the valve core movement of the feedback stage on the jet nozzle deflection, the stability and control precision of the recovery pressure $p_{c}$ will be greatly reduced. Therefore, the action of feedback stage of brake pressure servo valve is as follows: improve the stability and control precision of recovery pressure $p_{c}$, and suppress the positive feedback effect of oil return.

\section{Design of Two-Stage Brake Pressure Servo Valve}

To effectively restrain the vibration of the brake system, this paper redesigns the pressure feedback mechanism in the valve body to make the servo valve amplifier have a traditional two-sided structure; through improvement measures, there is no oil return positive feedback phenomenon in the servo valve. The possibility of a pressure positive feedback effect is completely eliminated, and a new structure of a twostage brake pressure servo valve is proposed.

\subsection{Structure Principle of Two-Stage Brake Pressure Servo} Valve. A two-stage brake pressure servo valve structure proposed in this paper is shown in Figure 10. The working principle of the two-stage brake pressure servo valve is as follows: when the torque motor does not receive the current signal, the jet pipe is vertical, and the flow of the jet nozzle enters the left/right receiving hole of the receiver evenly. The control pressure $p_{a}=p_{b}$ of the jet flow is formed at both ends of the main valve core. Meanwhile, the brake pressure feedback channel and the oil return pressure feedback channel are connected with the oil return port $\mathrm{H}$, that is, the feedback pressure on both sides of the main valve core $p_{a 1}=p_{b 1}=p_{h}$, at this time, the main valve core is located at the left end under the action of the right spring, and the brake port B is communicated with the oil return port $\mathrm{H}$. When after receiving the current signal, torque motor armature deflects, which drives the jet pipe to produce clockwise deflection, the coverage area of the jet nozzle to the left receiving hole is larger than that to the right receiving hole, jet flow on both ends of the main valve core formed by the control pressure is $p_{a}>p_{b}$, and the main valve core force balance is broken and moves forward under the action of differential pressure, brake port $\mathrm{B}$ communicates with oil supply port $\mathrm{P} 1$ and disconnects with oil return port $\mathrm{H}$, and the pressure oil enters the brake actuator through brake port $\mathrm{B}$ to form brake pressure. At this point, the feedback pressure $p_{b 1}$ on the right side of the main valve core is greater than the feedback pressure $p_{a 1}$ on the left side, forming a stable negative feedback effect on the main valve core, pushing the valve port between the brake port $B$ and the oil supply port $P_{1}$ to close, and reducing the brake pressure. Due to the inevitable overshoot in the brake pressure control process, the right feedback pressure $p_{b 1}$ is too large, which drives the main valve core to produce a large negative displacement; the brake port $\mathrm{B}$ is connected with the oil return port $\mathrm{H}$ and disconnected from the oil supply port $\mathrm{P}_{1}$, resulting in a decrease in the brake pressure and an increase in the oil return pressure; the feedback pressure $p_{a 1}$ on the left side of the main valve core increases, while the feedback pressure $p_{b 1}$ on the right side of the main spool decreases, forming stable negative feedback that hinders the further negative movement of the main spool. So reciprocating, a stable brake pressure output is formed.

The part of the jet amplifier of the two-stage brake pressure servo valve is a traditional bilateral control structure, which forms control pressure on both sides of the power valve core. Within the range of small deflection angle of the jet nozzle, the control pressure difference between the left and right cavities basically remains constant. Therefore, the two-stage brake pressure servo valve can form a stable control force on the power stage valve core without the negative feedback effect of the feedback stage on the control pressure; the two-stage brake pressure servo valve does not have the positive feedback effect of oil return, so it does not need the effect of weakening the positive feedback of oil return provided by the feedback stage. In summary, it can be judged that the two-stage brake pressure servo valve still has the ability to maintain control accuracy and stability after the cancellation of the feedback stage structure.

3.2. Dynamics Modeling of Two-Stage Brake Pressure Servo Valve. This section will establish the mathematical model of each part of the pressure servo valve and build the corresponding Matlab/Simulink simulation model. 


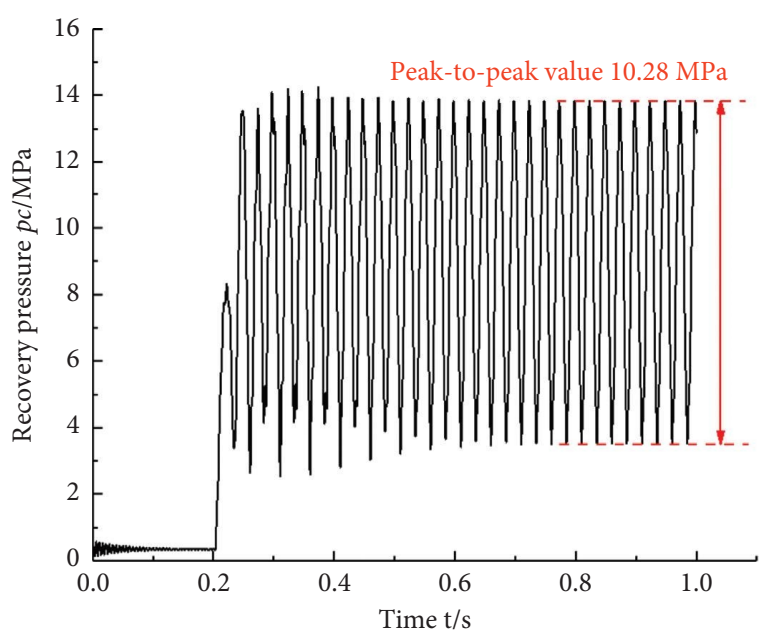

(a)

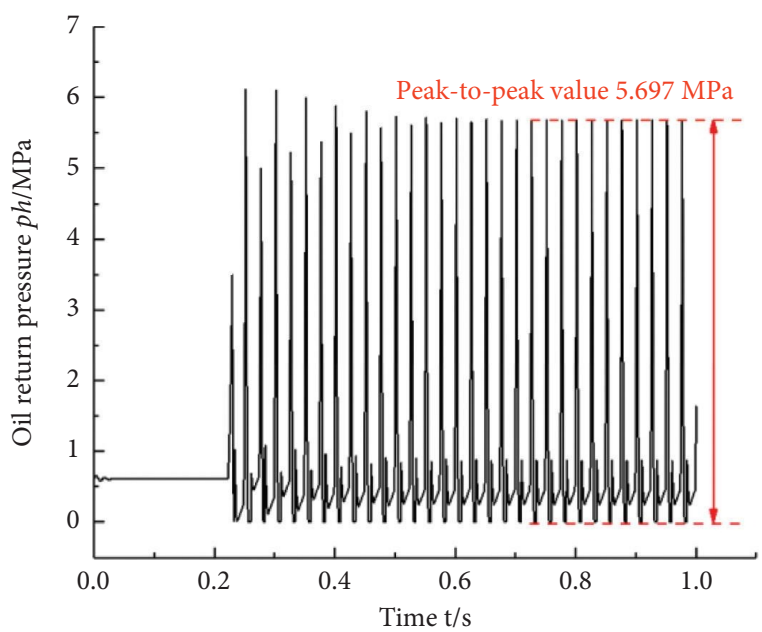

(c)

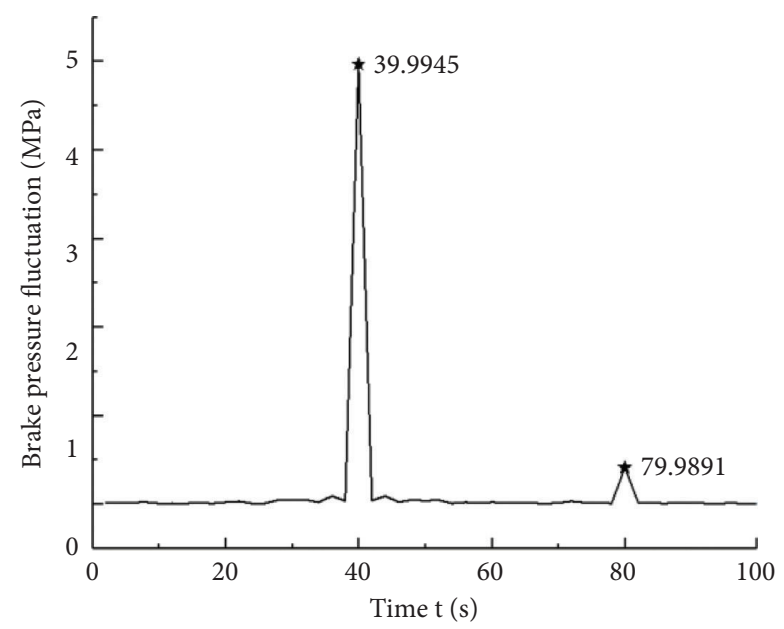

(b)

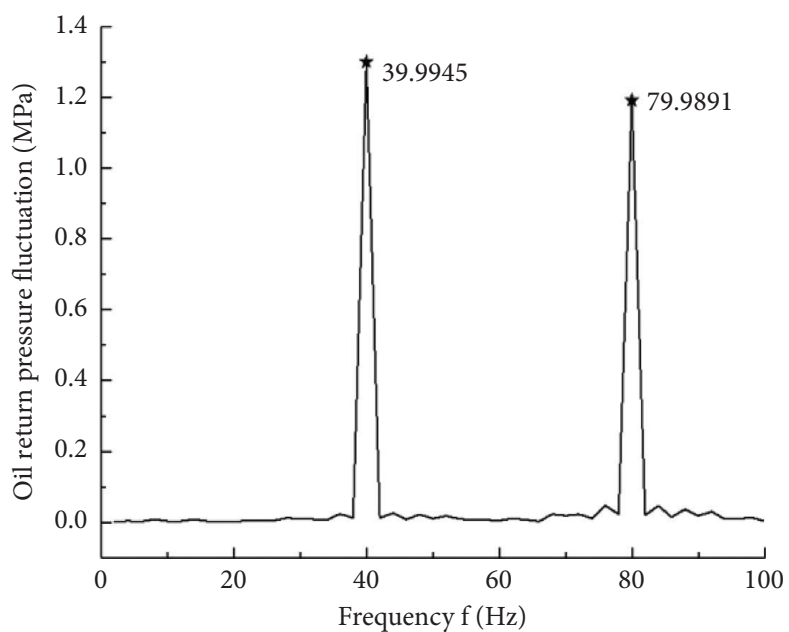

(d)

FIGURE 9: Simulation results of the front stage under fixed return oil pressure. (a) Brake pressure $p_{b}$. (b) Brake pressure $p_{b}$ FFT spectrum. (c) Oil return pressure $p_{h}$. (d) Oil return pressure $p_{h}$ FFT spectrum.

The dynamics model of torque motor is built as follows:

$$
\begin{aligned}
T_{d} & =K_{t} \cdot \Delta i+K_{m} \cdot \theta, \\
T_{d} & =J_{a} \frac{d^{2} \theta}{\mathrm{d} t^{2}}+B_{a} \frac{\mathrm{d} \theta}{\mathrm{d} t}+K_{a} \theta, \\
Q_{f} & =k_{q} r \theta-k_{c} p_{L}, \\
\dot{p}_{L} & =\frac{\beta}{V_{c v}}\left(Q_{f}-A_{1} \dot{x}_{v}\right),
\end{aligned}
$$

where $T_{d}$ is the electromagnetic moment $(\mathrm{Nm}) ; \psi$ is the deflection angle of jet pipe (rad). $K_{m}$ is the magnetic torque spring stiffness $(\mathrm{N} / \mathrm{m}) . \Delta i$ is the control current (A). $K_{t}$ is the electromagnetic moment coefficient (Nm/A). $J_{a}$ is the moment of inertia of armature jet pipe assembly $\left(\mathrm{Kg} / \mathrm{m}^{2}\right)$. Ba is the damping coefficient of armature jet pipe assembly $(\mathrm{Nm} / \mathrm{rad} / \mathrm{s})$. Ka is spring tube stiffness. $Q_{f}$ is the load flow rate of jet pipe. $k_{q}$ is jet nozzle linear flow coefficient $\left(\mathrm{m}^{2} / \mathrm{s}\right) . k_{c}$ is the linear flow rate/pressure gradient of the jet nozzle $\left(\mathrm{m}^{3} / \mathrm{sPa}\right) . r$ is the length of jet nozzle $(\mathrm{m}) \cdot p_{L}$ is the load pressure of the jet amplifier $(\mathrm{Pa})$. $\beta$ is the bulk elastic modulus of oil (Pa). $V_{c v}$ is the outlet chamber of the jet nozzle $\left(\mathrm{m}^{3}\right) . A_{1}$ is the area acting on the load pressure of the jet amplifier $\left(\mathrm{m}^{2}\right) . x_{v}$ is the displacement of the power stage valve core $(\mathrm{m})$.

The dynamic equation of the power stage valve core is as follows:

$$
\begin{aligned}
p_{L} A_{1}+p_{h} A_{2}-p_{b} A_{2}= & M_{v} \frac{\mathrm{d}^{2} x_{v}}{\mathrm{~d} t^{2}}+B_{v} \frac{\mathrm{d} x_{v}}{\mathrm{~d} t} \\
& +K\left(x_{v}+x_{v 0}\right)+K_{f} x_{v} \\
Q= & C_{d} W x_{v} \sqrt{\frac{2}{\rho} p_{v L}}
\end{aligned}
$$

where $p_{b}$ is brake pressure ( $\left.\mathrm{Pa}\right) . p_{h}$ is the oil return pressure. $A_{2}$ is the pressure feedback area of the power stage valve core 


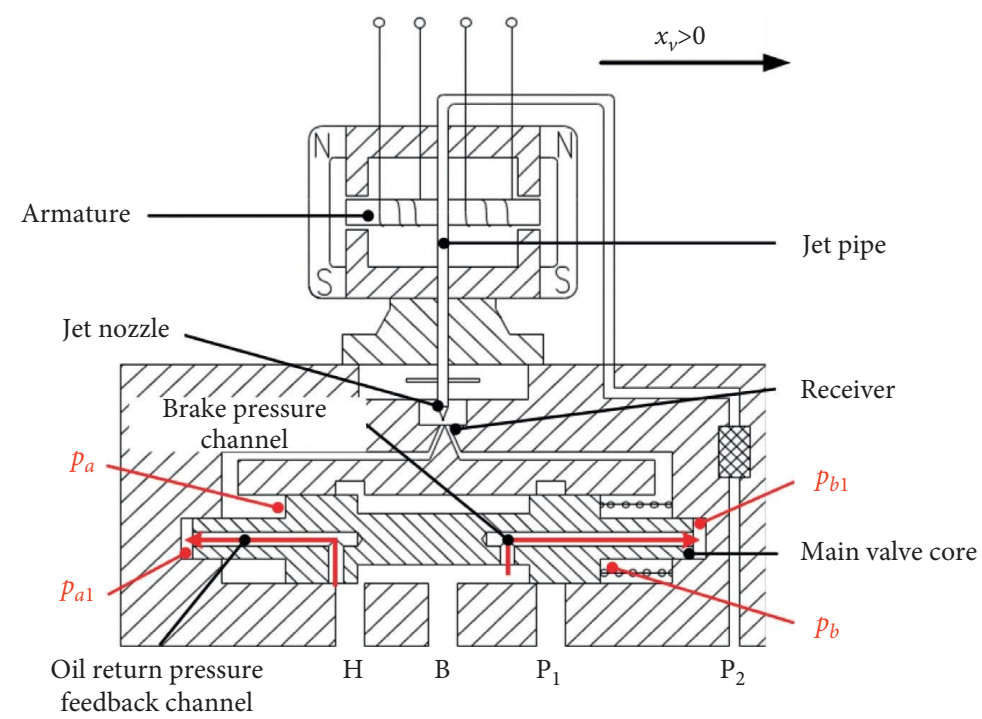

Figure 10: Two-stage brake pressure servo valve structure.

$\left(\mathrm{m}^{2}\right) . M_{v}$ is the power stage valve core mass $(\mathrm{kg}) . B_{v}$ is the damping coefficient of the power stage valve core $(\mathrm{Nm} / \mathrm{rad} /$ s). $K$ is the spring stiffness of the power stage valve core $(\mathrm{N} /$ $\mathrm{m}) . x_{v 0}$ is the initial compression of the power stage valve core spring $(\mathrm{m}) . K_{f}$ is the steady-state hydraulic dynamic stiffness of the power stage valve core $(\mathrm{N} / \mathrm{m}) . C_{d}$ is the flow coefficient of the power stage valve core. $\mathrm{W}$ is the area gradient of the power stage valve core. $x_{v}$ is the displacement of the valve core at the power stage $(\mathrm{m}) . Q$ is the load flow rate of the power stage valve core $\left(\mathrm{m}^{3} / \mathrm{s}\right)$. pvL is the power stage valve core load differential pressure $(\mathrm{Pa})$.

The mathematical model of load characteristics is shown as follows:

$$
\begin{aligned}
Q_{L} & =C_{d} W x_{v} \sqrt{\frac{2}{\rho}\left(\frac{1+\operatorname{sign}\left(x_{v}\right)}{2} p_{s}+\frac{-1+\operatorname{sign}\left(x_{v}\right)}{2} p_{h}-\operatorname{sign}\left(x_{v}\right) p_{b}\right)}, \\
Q_{L} & =A_{g} \frac{\mathrm{d} y}{\mathrm{~d} t}+\frac{V_{g b}}{\beta} \frac{\mathrm{d} p_{b}}{\mathrm{~d} t}+C_{b} p_{b}, \\
A_{g} p_{b} & =M_{g} \frac{\mathrm{d}^{2} y}{\mathrm{~d} t^{2}}+B_{g} \frac{\mathrm{d} y}{\mathrm{~d} t}+K_{g} y,
\end{aligned}
$$

where $Q_{L}$ is the load flow rate $\left(\mathrm{m}^{3} / \mathrm{s}\right)$. Ps is the oil supply pressure $(\mathrm{Pa}) . A_{g}$ is the effective area of the piston of the brake actuator $\left(\mathrm{m}^{2}\right) \cdot y$ is the displacement of the piston rod of the brake actuator $(\mathrm{m}) . V_{g b}$ is the brake capacity cavity $\left(\mathrm{m}^{3}\right)$ composed of the rodless cavity of the brake actuator and the hydraulic pipe. $C_{b}$ is a brake actuator leakage system $\left(\mathrm{m}^{3} / \mathrm{s} \cdot \mathrm{Pa}\right) . M_{g}$ is the mass of the actuator piston $(\mathrm{kg}) . \mathrm{Bg}$ is the viscosity damping coefficient of the actuator piston $(\mathrm{Nm} /$ $\mathrm{rad} / \mathrm{s}) . K_{g}$ is the actuator spring stiffness $(\mathrm{N} / \mathrm{m})$.

The mathematical model of the oil return channel is shown as follows:

$$
\begin{aligned}
\dot{p}_{h} & =\frac{\beta}{V_{h}}\left(Q_{a}-A\left(x_{j}\right) C_{d j} \sqrt{\frac{2}{\rho} p_{h}}\right), \\
\dot{p}_{c j} & =\frac{\beta}{V_{c j}}\left(Q_{c}-A_{j} \dot{x}_{j}\right), \quad+B_{j} \dot{x}_{j}+K_{j} x_{j}+K_{j} x_{j 0}+k_{s} x_{j} p_{h}, \\
p_{c j} A_{j} & =M_{j} \ddot{x}_{j}
\end{aligned}
$$


where $A\left(x_{j}\right)$ is the flow area of the relief valve port $\left(\mathrm{m}^{2}\right) . V_{h}$ is the volume of the oil return chamber. $C_{d j}$ is the flow coefficient of the relief valve. $x_{j}$ is the overflow valve core displacement $(\mathrm{m}) . Q_{a}$ is the overflow valve flow rate $\left(\mathrm{m}^{3} / \mathrm{s}\right)$. $p_{c j}$ is the relief valve to control the cavity pressure $(\mathrm{PA}) . \mathrm{V}_{\mathrm{cj}}$ is the overflow valve control chamber volume $\left(\mathrm{m}^{3}\right) . Q_{c}$ controls the flow rate of the cavity for the relief valve $\left(\mathrm{m}^{3} / \mathrm{s}\right) . A_{j}$ is the relief valve control pressure action area $\left(\mathrm{m}^{2}\right) . K_{s}$ is the steady-state fluid dynamic coefficient of the overflow valve core (N/MPa). $M_{j}$ is the mass of the moving parts of the relief valve $(\mathrm{kg}) . B_{j}$ is the relief valve damping coefficient $(\mathrm{Nm} / \mathrm{rad} /$ s). $K_{j}$ is the relief valve pressure regulating spring stiffness $(\mathrm{N} / \mathrm{m}) . x_{j 0}$ is the initial compression of the relief valve pressure regulating spring $(\mathrm{m})$.

According to the dynamics model of the braking pressure servo valve-controlled cylinder system [23], the simulation model was built on the MATLAB/Simulink software platform, as shown in Figure 11.

\section{Simulation Analysis of Multivalve Parallel Brake Servo Control System}

4.1. Simulation Modeling of Six-Valve Parallel System. The six-valve parallel brake servo control system is shown in Figure 12. In the system, 6 brake pressure servo valves in three sets of brake pressure servo valves independently control 6 brake actuators, so 6 brake pressure channels in the system are independent of each other and do not affect each other. However, the two brake pressure servo valves in each brake pressure servo valve group in the system share one oil supply channel, and the different oil supply channels are supplied by the same hydraulic oil source. Therefore, when the oil source fluctuates, the effects of each brake pressure servo valve are basically the same. In the oil return channel, two brake pressure servo valves in each group share one oil return channel, and the oil returns of each brake pressure servo valve group are summarized in the same oil return channel. Therefore, when fluctuation occurs in the oil return channel, it will affect all the brake pressure servo valves in the system at the same time.

According to the structure of the 6-valve parallel brake servo control system in Figure 12, we take the input current signal as the system input, with the brake pressure servo valve power stage load flow as the output. The MATLAB/ Simulink dynamic model of the brake pressure servo valve cylinder control system is integrated into the brake servo valve cylinder control system submodule, and the MATLAB/ Simulink model of the brake servo control system under the condition of 6-valve parallel is built, as shown in Figure 13.

4.2. Simulation Analysis of Six-Valve Parallel System. In the case of the same brake pressure servo valve cylinder control system, two, three, four, five, and six two-stage brake pressure servo valves are opened, respectively. Under the action of $40 \mathrm{~mA}$ step current and oil supply pressure of $15 \mathrm{MPa}$ and $21 \mathrm{MPa}$, the obtained brake pressures are shown in Figures 14 and 15. It can be seen that the two-stage brake pressure servo valve-controlled cylinder system can still maintain fast and stable output of brake pressure under the condition of multiple valves in parallel. At the same time, the number of parallel valves in the system has almost no effect on the braking pressure output, and the sensitivity of the output of the multivalve parallel braking system to the number of parallel valves is very low. Combined with the above simulation results, the two-stage brake pressure servo valve can effectively restrain the vibration of the multivalve parallel brake system.

\section{Experiment of Two-Stage Brake Pressure Servo Valve-Controlled Cylinder System}

5.1. Multivalve Parallel Brake System Test Platform. In order to verify the vibration suppression effect of the two-stage brake pressure servo valve, a new brake pressure servo valve prototype was designed, as shown in Figure 16. In large aircraft multivalve parallel brake valve control system, multiple sets of brake pressure servo valve control cylinder systems usually work in parallel, and after the parallel connection, the oil return flow in the system surges, the coupling effects of the brake pressure servo valve control cylinder system, structure difference, and other factors all can have an important influence on the characteristics of the parallel braking system. Therefore, it is necessary to carry out a detailed analysis of the multivalve parallel connection through the multivalve parallel test platform.

The experimental platform is built according to the schematic diagram in Figure 12. The test platform consists of three servo valve sets, four pressure sensors, brake cavity, oil inlet and outlet, etc. The hydraulic oil enters from the oil inlet on the right, passes through three servo-valve sets, and finally flows out of the oil outlet into a pipe. As shown in Figure 17, pressure sensor 4 in this test platform is connected to the second pipe of the brake chamber to test the pressure of the brake chamber. Pressure sensors 1, 2, and 3, respectively, test the oil return pressure of the oil return ports of the three servo-valve sets. The oil supply pressure in this experiment is provided by the hydraulic pump set outside the experimental platform, and the oil return backpressure is set by manually adjusting the relief valve. In this experiment, signals are collected through four sensors.

The basic parameters such as hydraulic pipeline and load are shown in Table 1.

5.2. Experiment of Two-Stage Brake Pressure Servo ValveControlled Cylinder System. Under $20 \mathrm{~mA}$ step, $40 \mathrm{~mA}$ step, and $40 \mathrm{~mA}$ slope current signals, the output pressure of the two-stage brake pressure valve is measured, as shown in Figure 18. It can be seen that the simulation results of the two-stage brake pressure servo valve are in good agreement with the experimental results in terms of brake pressure stability, rise time, overshoot, and so on. However, because the comprehensive characteristic equation of the jet nozzle is used in the simulation analysis model, there is a certain difference between the establishment processes of the load pressure difference of the jet nozzle in the simulation analysis and the reality, which results in a certain error 


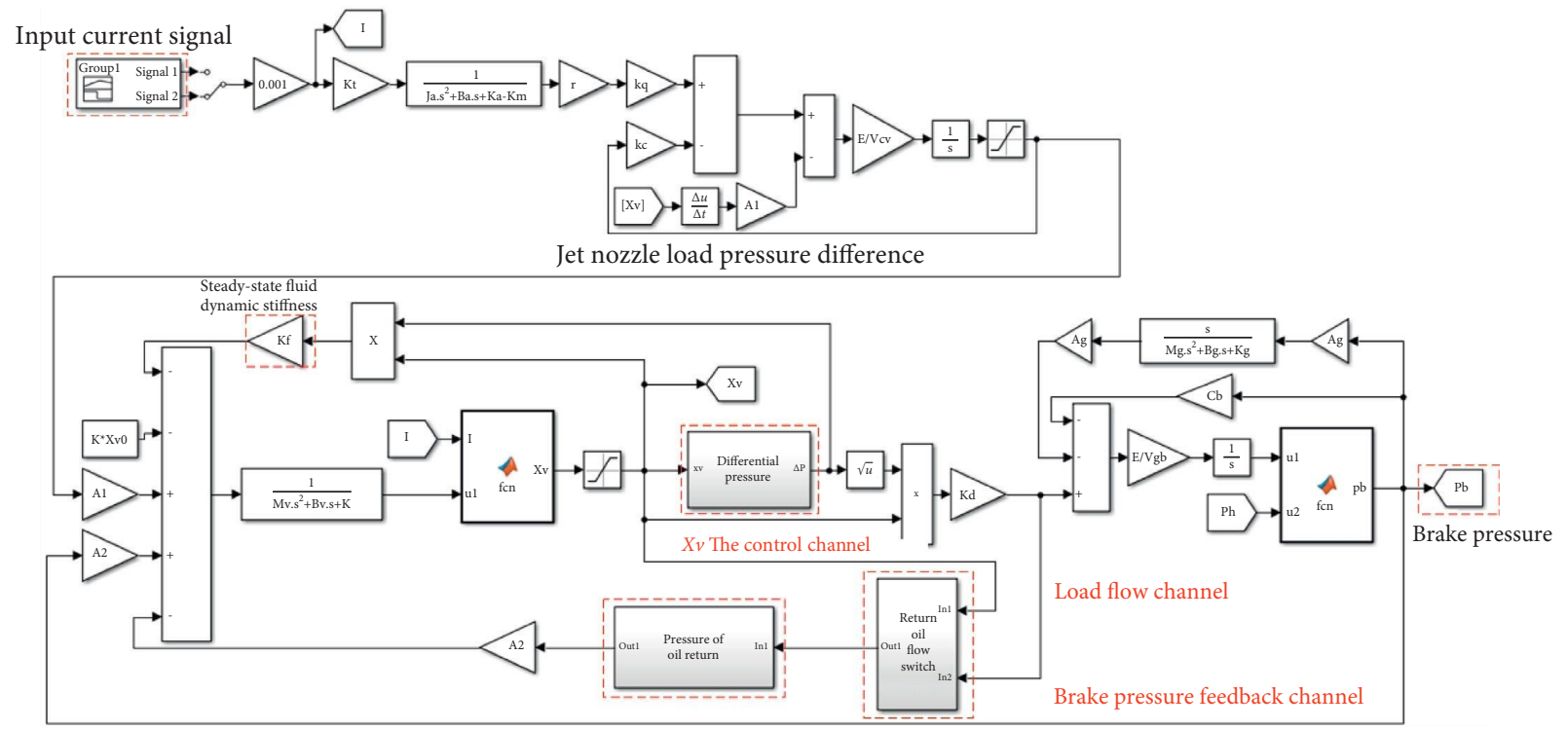

Figure 11: MATLAB/Simulink model of brake pressure servo valve-controlled cylinder system.

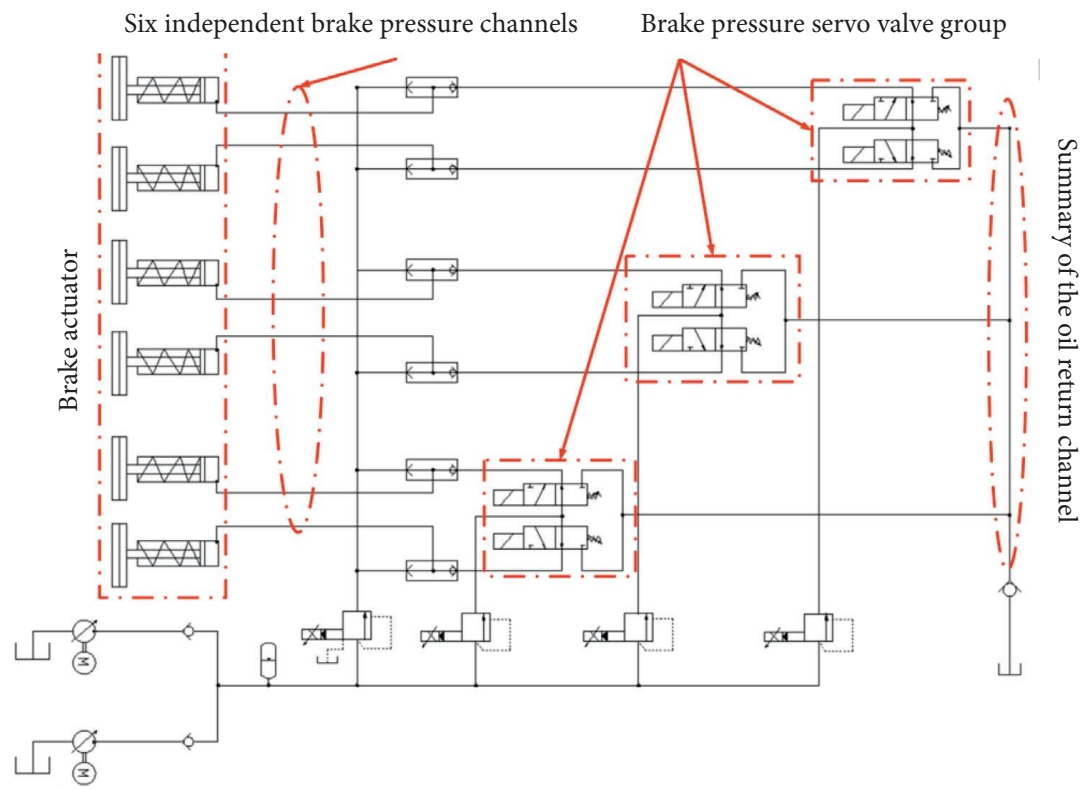

FIGURE 12: 6-valve parallel brake servo control system.

between the simulation analysis results and the experimental results in the braking pressure rise stage.

In order to compare the phenomenon of braking pressure agitation of two-stage brake pressure servo valve with that of three-stage brake pressure servo valve, the experimental results of output pressure of both are drawn in the same figure, as shown in Figure 19.

It can be seen that although the output brake pressure of the two-stage brake pressure servo valve fluctuates, the waveform, amplitude, and frequency domain characteristics are obviously different from the constant amplitude selfexcited oscillation of the three-stage brake pressure servo valve. As shown in Figure 19(b), the frequency domain curve of the two-stage brake pressure servo valve shows that its main frequency component is more complex than the selfexcited oscillation waveform of the original brake pressure servo valve: there were three peaks with similar amplitude in the range of $0 \sim 60 \mathrm{~Hz}$. As a result, the oscillation waveform of the two-stage brake pressure servo valve is more chaotic and presents a trend of random oscillation rather than periodic constant amplitude oscillation. Therefore, the small fluctuation of the output brake pressure of the two-stage brake pressure servo valve is not the self-excited oscillation described above, but an inherent feature determined by the 


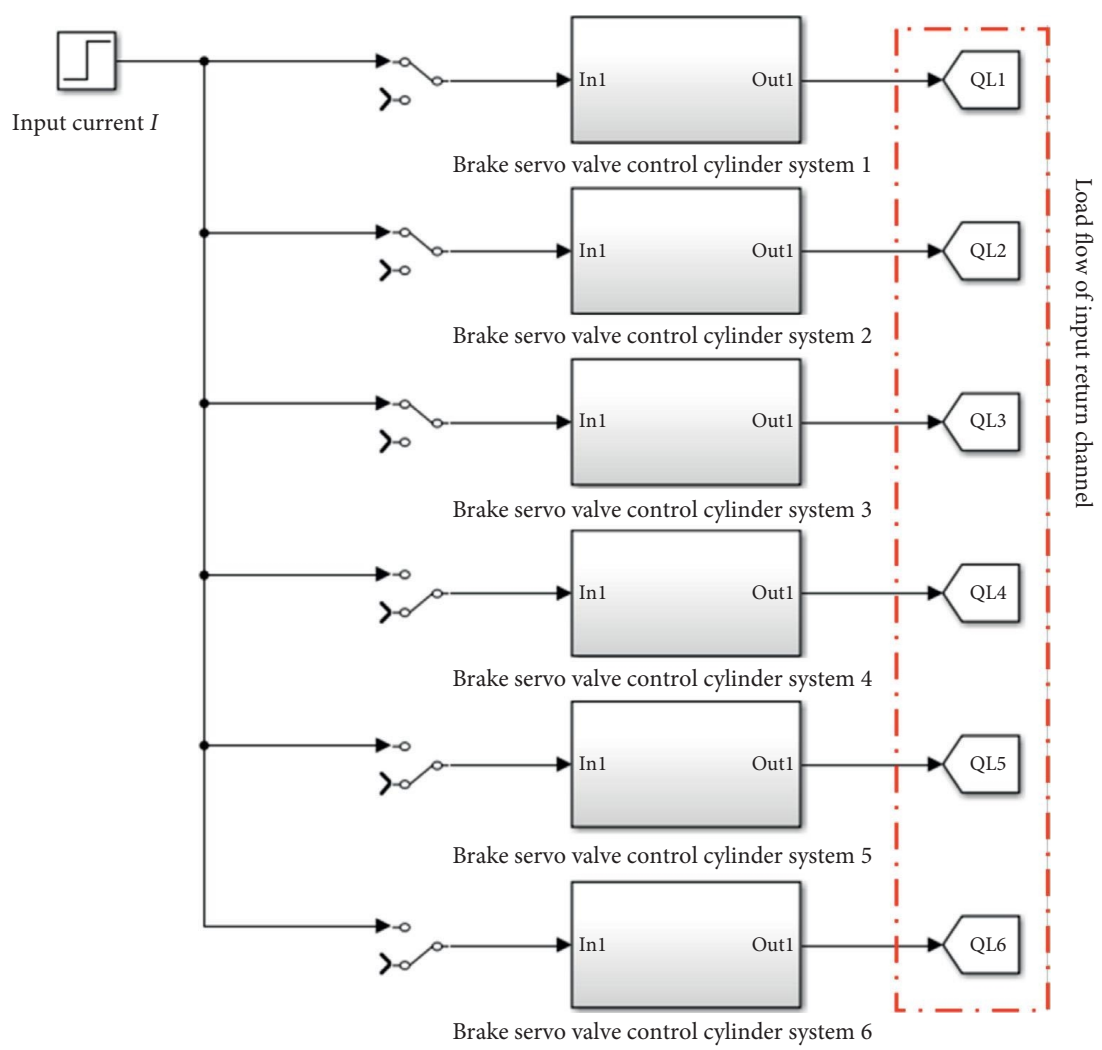

(a)

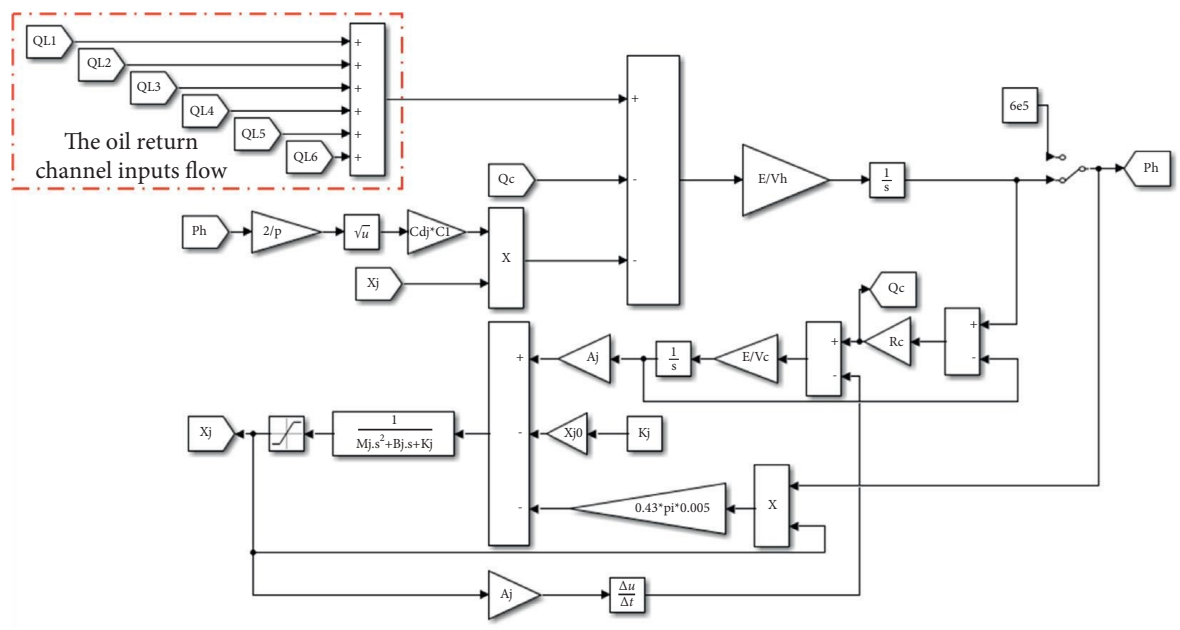

(b)

FiguRE 13: MATLAB/Simulink model of the 6-valve parallel brake control system. (a) Six sets of brake servo valve-controlled cylinder parallel system. (b) Oil return channel model.

working principle of the brake pressure servo valve. At the same time, it is observed that the fluctuation range of the brake pressure output by the two-stage brake pressure servo valve is very small, which can be approximately considered as the constant pressure output.

\subsection{Experiment of Several Sets of Two-Stage Brake Pressure} Servo Valve-Controlled Cylinder System. In order to compare with the test results of a single two-stage brake pressure servo valve-controlled cylinder system, first of all, the test was carried out under the oil supply pressure of $15 \mathrm{MPa}$. Under the $40 \mathrm{~mA}$ step current signal, different numbers of two-stage brake pressure servo valves are opened, and the measured brake pressure output by the system is shown in Figure 20.

It can be seen that when the oil supply pressure is $15 \mathrm{MPa}$, and the two-stage brake pressure servo valve can quickly form a stable output of brake pressure under the condition of multiple valves in parallel.

Then, we adjust the fuel supply pressure to $21 \mathrm{MPa}$. Under the $40 \mathrm{~mA}$ step current signal, different numbers of 


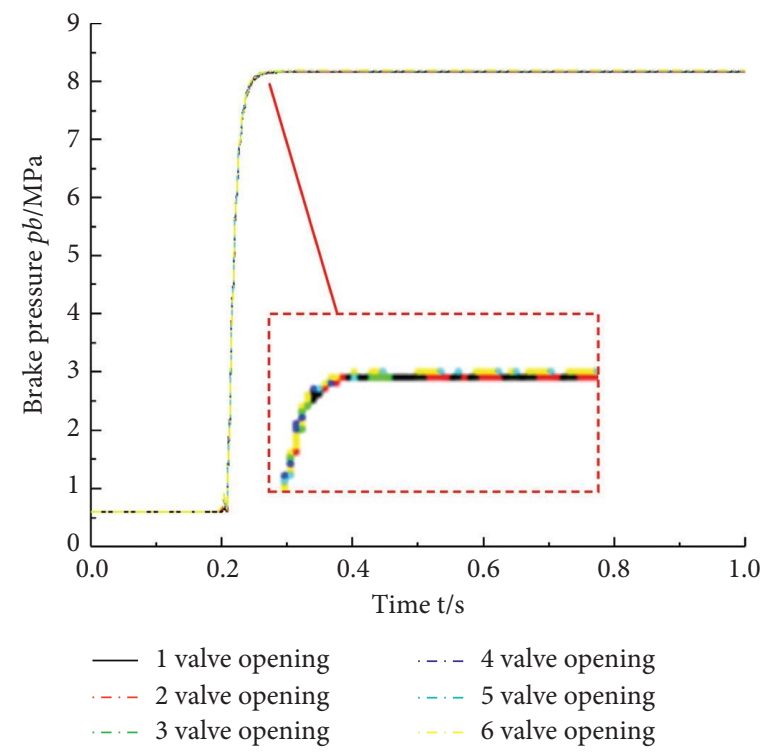

FIgURE 14: Pressure output of two-stage brake pressure servo valve with multiple valves in parallel at $15 \mathrm{MPa}$ oil supply.

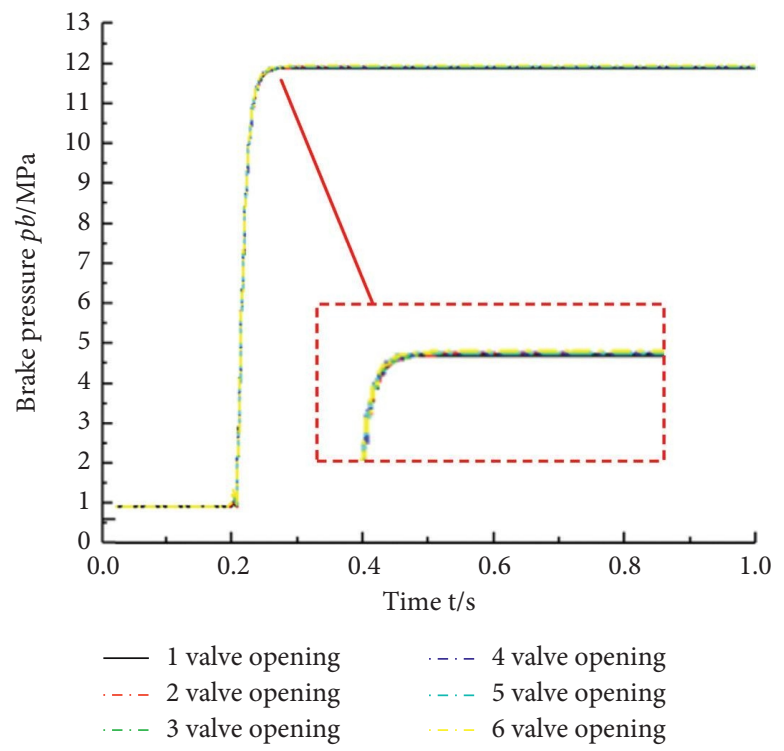

Figure 15: Pressure output of two-stage brake pressure servo valve with multiple valves in parallel at 21 MPa oil supply.

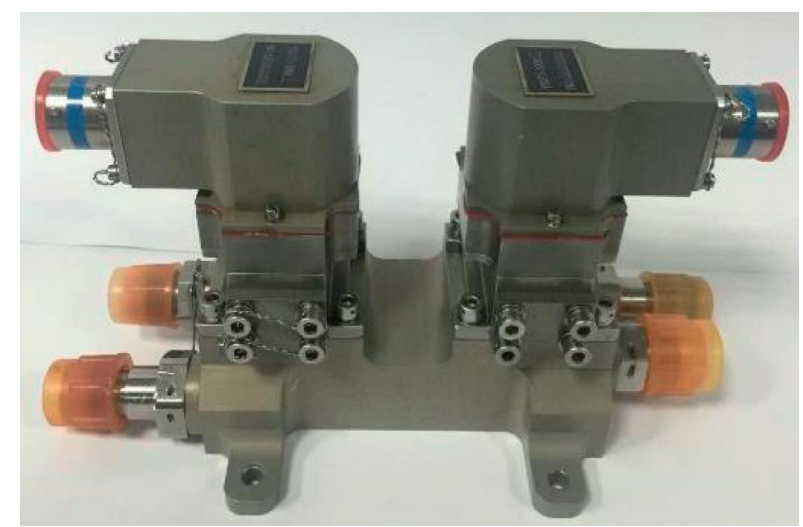

FIGURE 16: The new brake pressure servo valve. 


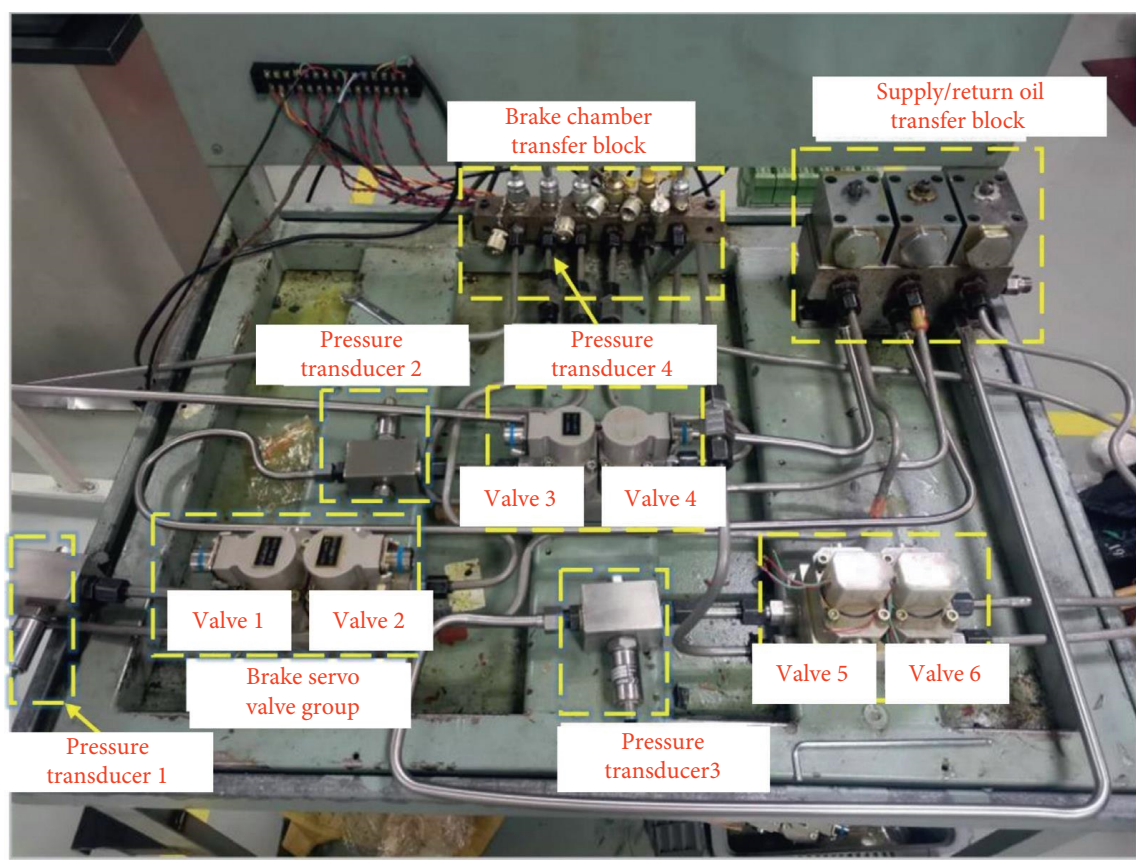

Figure 17: The test platform for the multivalve brake system.

Table 1: Parameters of the test platform.

\begin{tabular}{lcccccc}
\hline $\begin{array}{l}\text { Oil supply pressure } \\
(\mathrm{MPa})\end{array}$ & System flow & Brake pipe $(\mathrm{m})$ & Oil return pipe $(\mathrm{m})$ & $\begin{array}{c}\text { Oil return pressure } \\
(\mathrm{MPa})\end{array}$ & $\begin{array}{c}\text { Load stiffness } \\
\text { damping }\end{array}$ \\
\hline 15 & $6.25 e-4 \mathrm{~m}^{3} / \mathrm{s}$ & $\varphi 0.006 \times 1.50$ & $\varphi 0.006 \times 1.01$ & 0.6 & $1000000 \mathrm{~N} / \mathrm{m}$ & $50 \mathrm{~N} \mathrm{~s} / \mathrm{m}$ \\
\hline
\end{tabular}

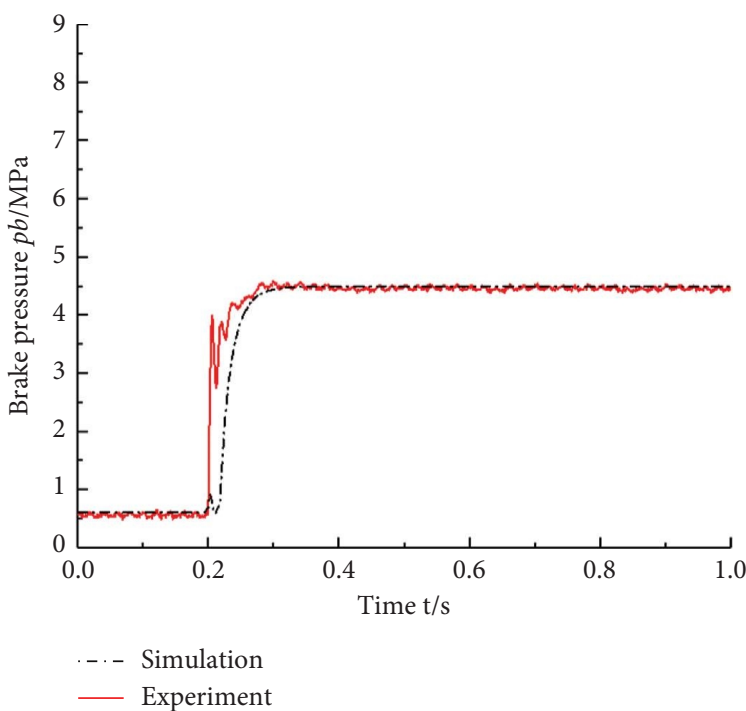

(a)

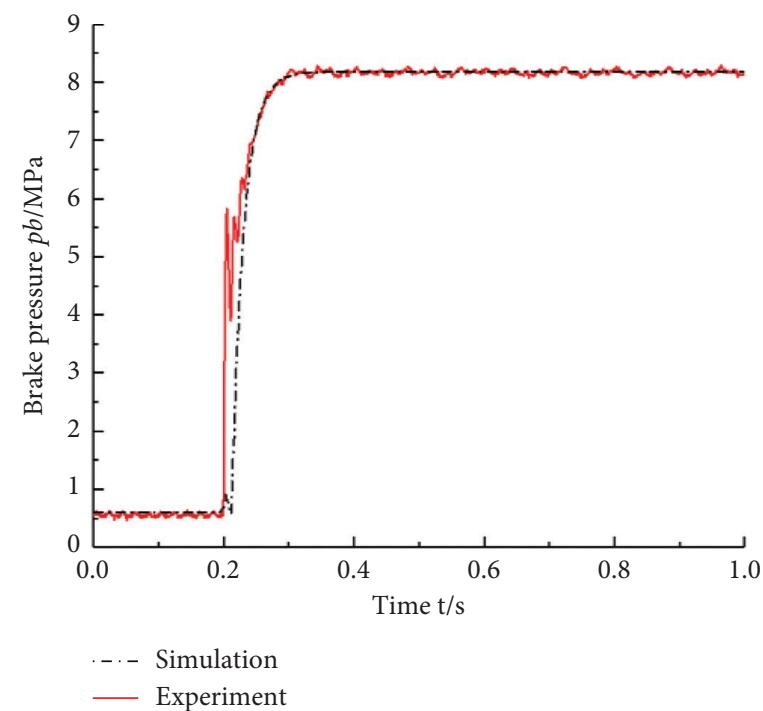

(b)

Figure 18: Continued. 


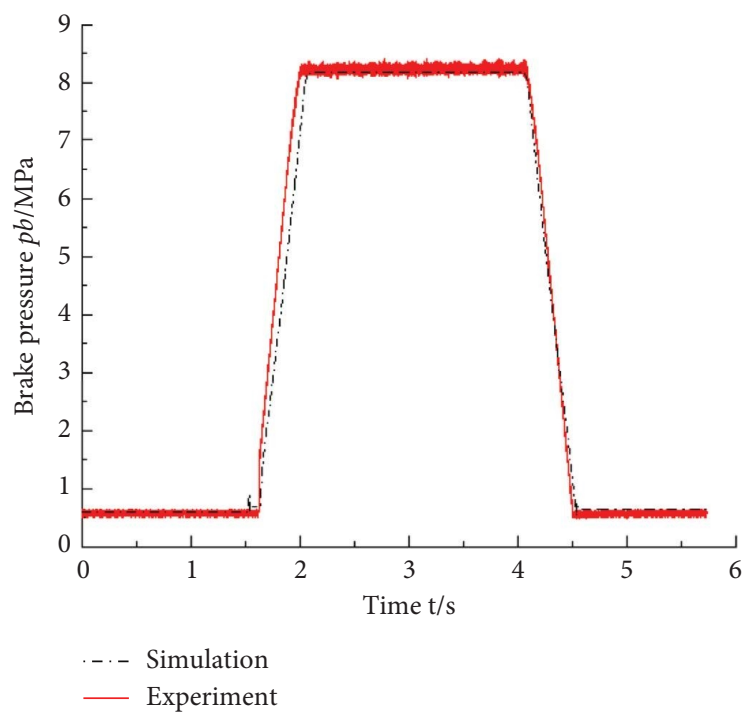

(c)

FigURe 18: Test results of two-stage brake pressure servo valve. (a) $20 \mathrm{~mA}$ step current input. (b) $40 \mathrm{~mA}$ step current input. (c) $40 \mathrm{~mA}$ ramp current input.

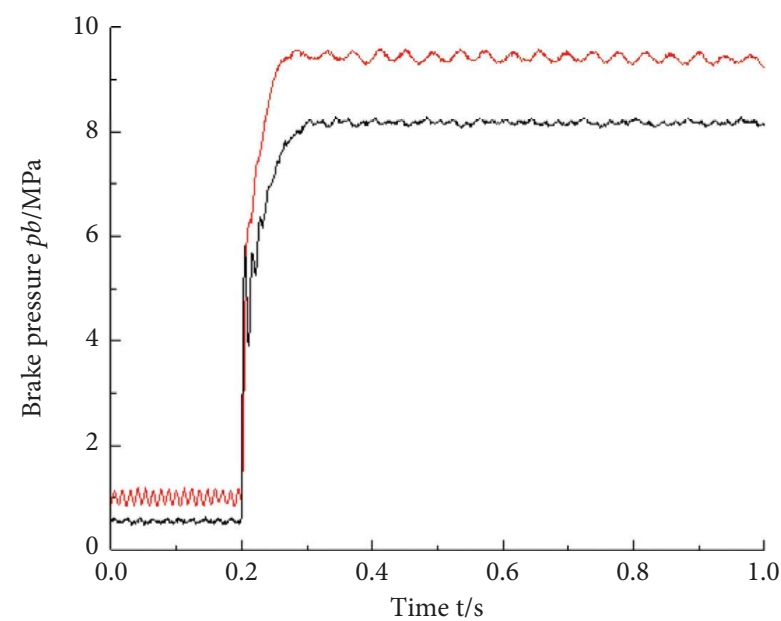

Prototype brake pressure servo valve New brake pressure servo valve

(a)

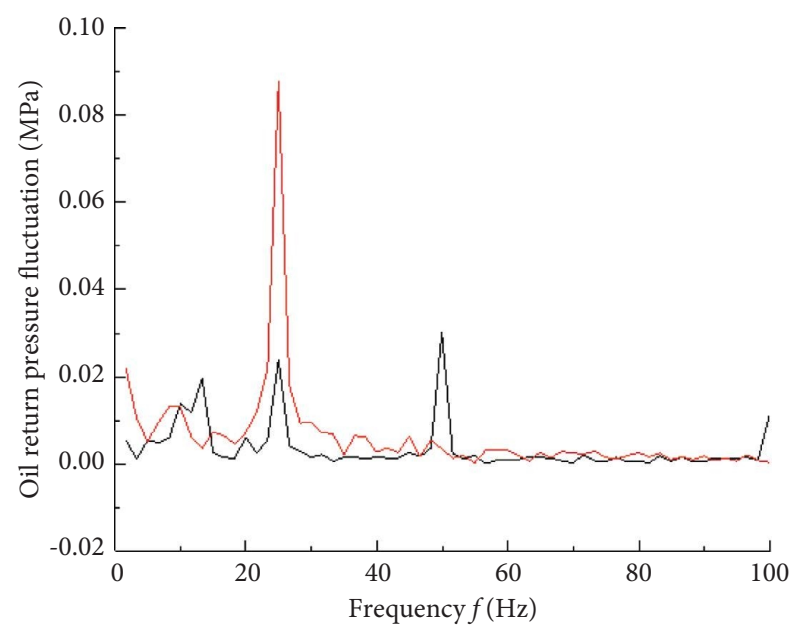

Prototype brake pressure servo valve New brake pressure servo valve

(b)

FIGURE 19: Comparison of experimental results of brake pressure. (a) Brake pressure time domain curve. (b) Brake pressure frequency domain curve.

two-stage brake pressure servo valves are opened. The measured brake pressure output by the system is shown in Figure 21.

It can be seen that when the oil supply pressure is increased to $21 \mathrm{MPa}$, the two-stage brake pressure servo valve can still maintain a stable output of brake pressure under the condition of multivalve parallel. However, with the different numbers of parallel valves in the system, the brake pressure oscillates slightly, which is a normal phenomenon caused by the working principle of the brake pressure servo valve itself.

Through the experimental results, it is found that no matter how many valves are used in parallel in the system, the brake pressure will appear slight oscillation phenomenon, and the stable oscillation section has an irregular difference, which is due to the normal fluctuation caused by the working principle of the brake pressure servo valve itself 


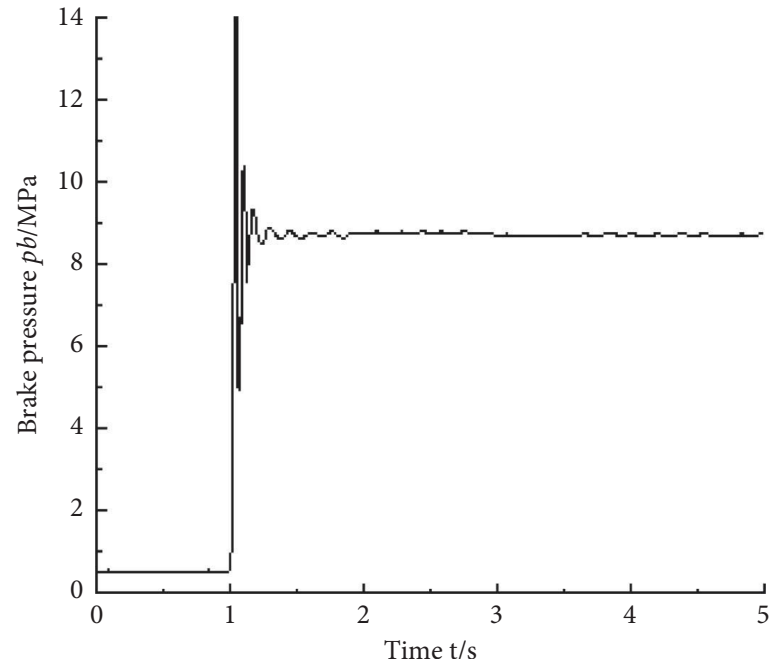

(a)

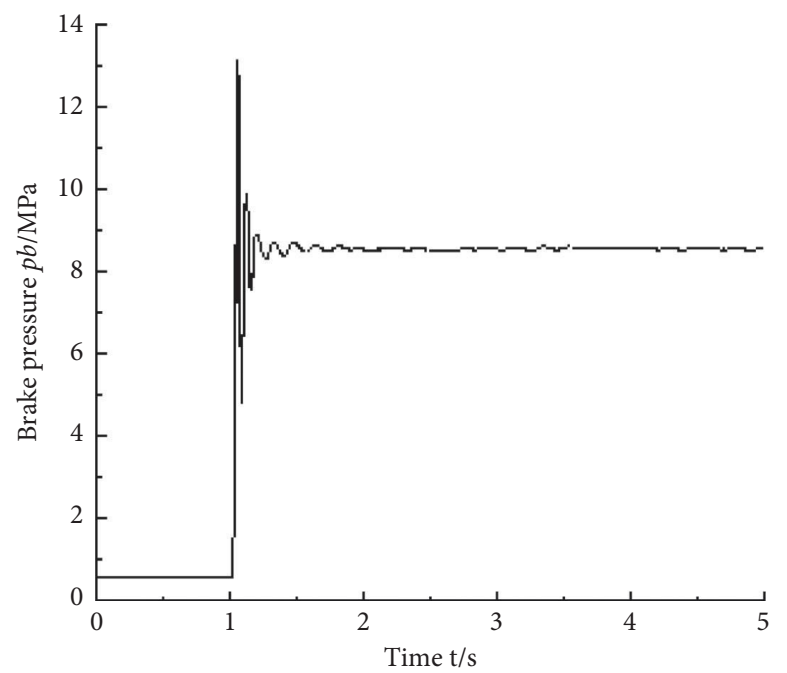

(c)

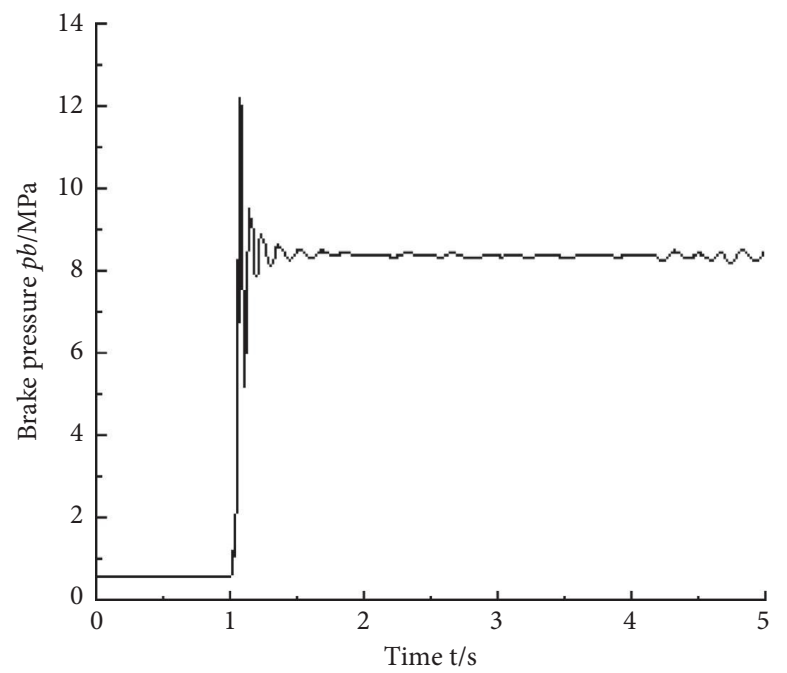

(e)

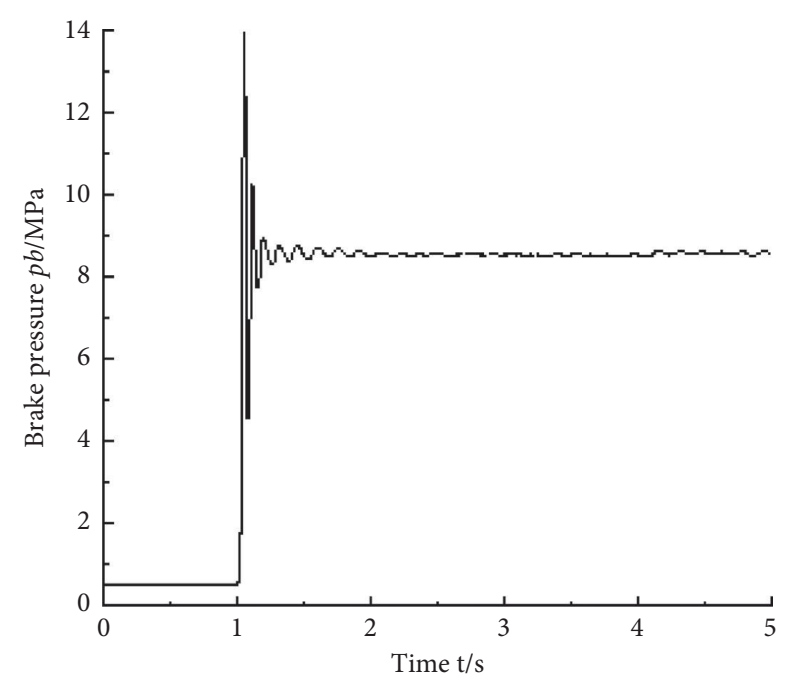

(b)

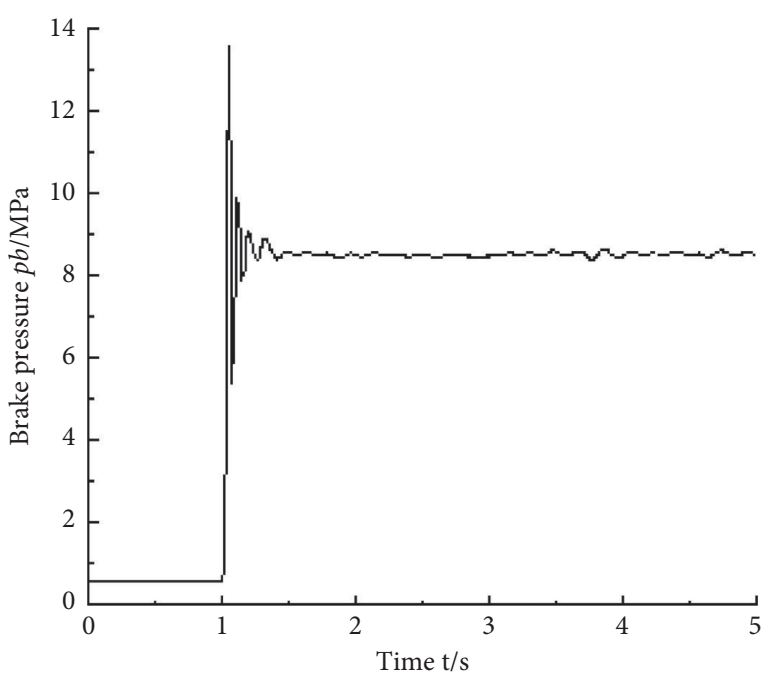

(d)

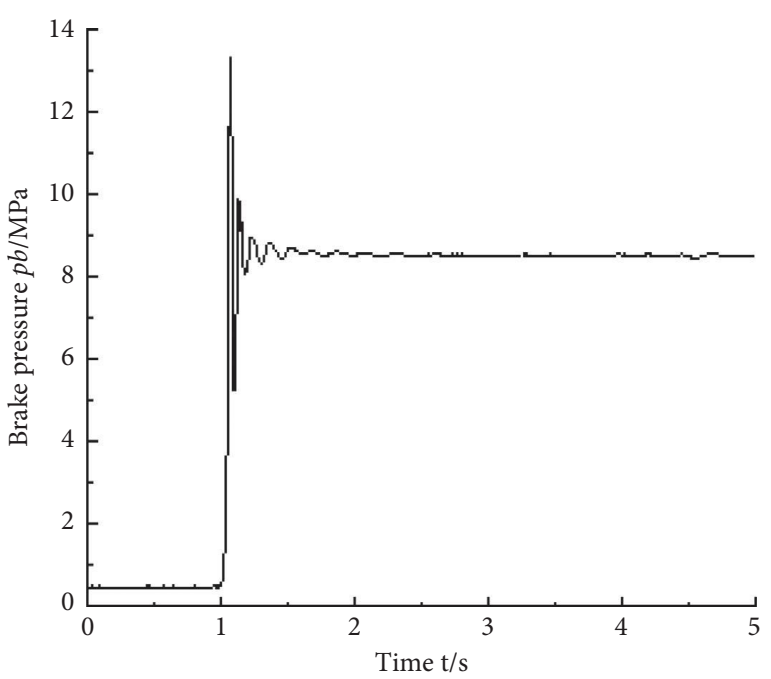

(f)

Figure 20: Pressure output of two-stage brake pressure servo valve-controlled cylinder system at $15 \mathrm{MPa}$ oil supply pressure. (a) 1-valve opening. (b) 2-valve opening. (c) 3-valve opening. (d) 4-valve opening. (e) 5-valve opening. (f) 6-valve opening. 


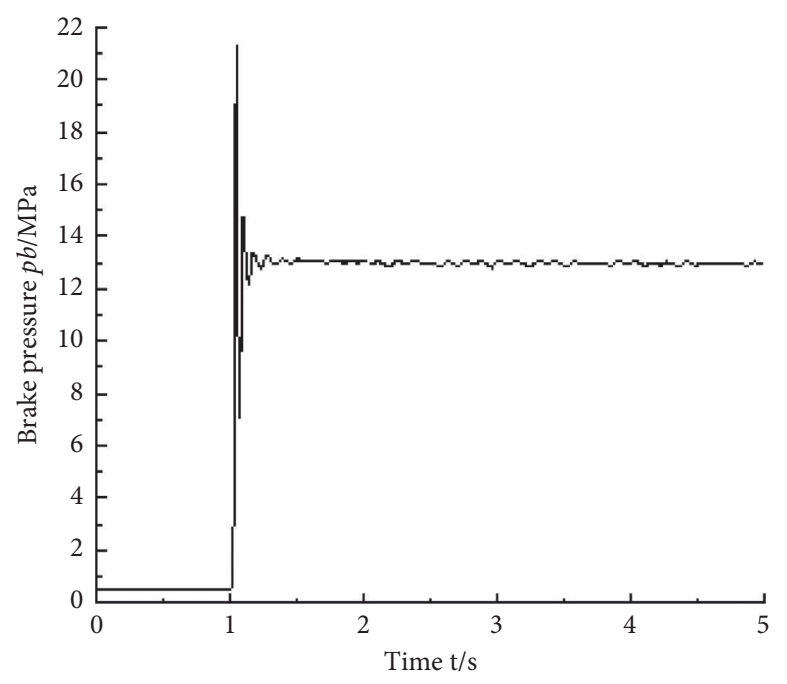

(a)

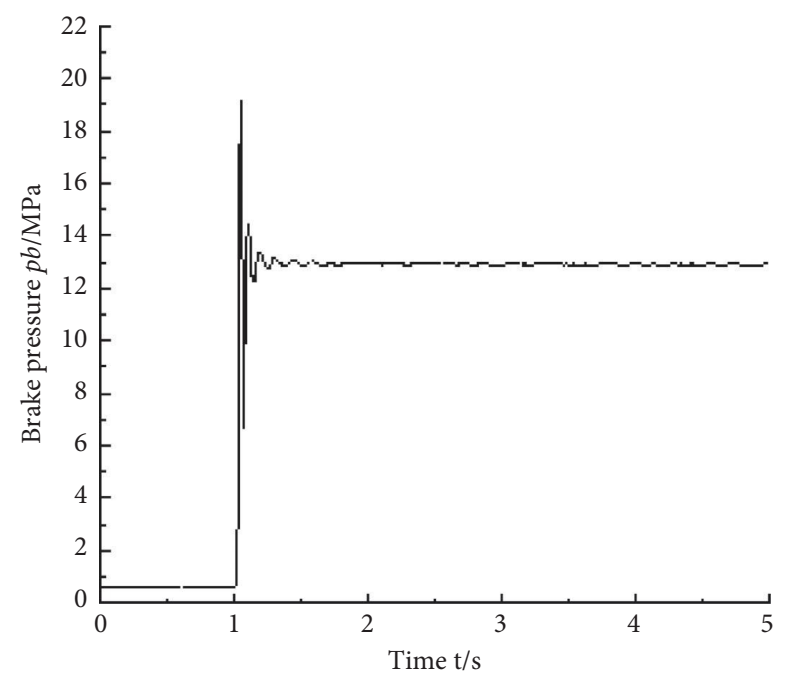

(c)

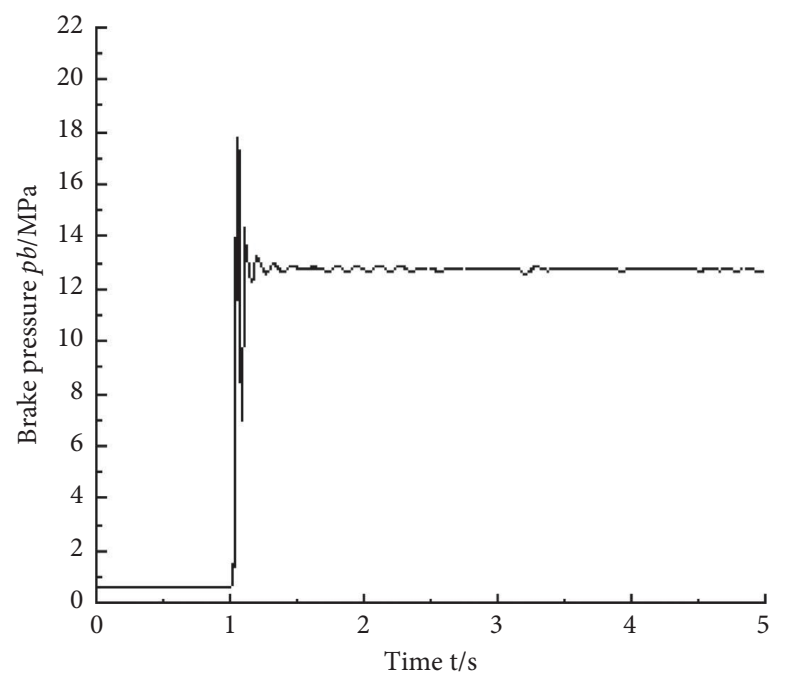

(e)

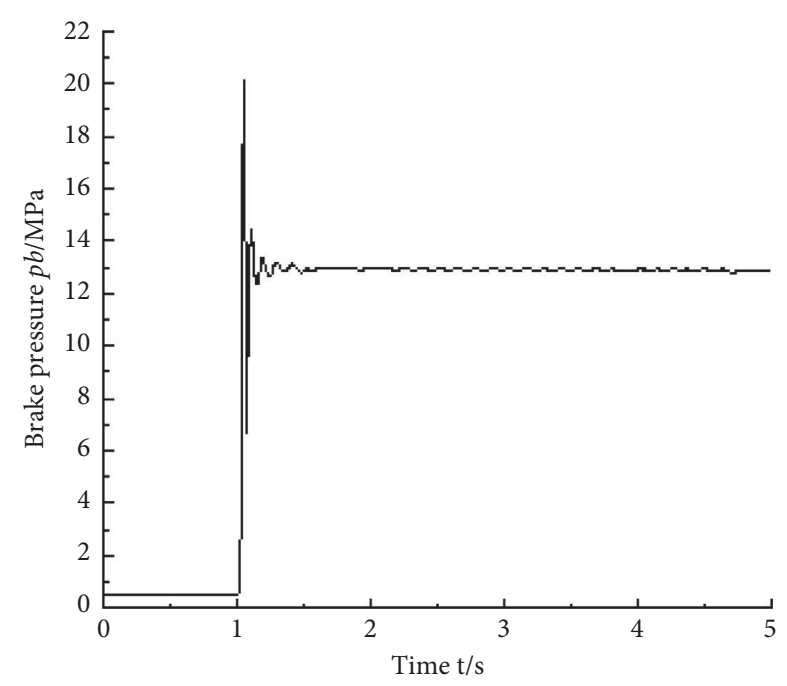

(b)

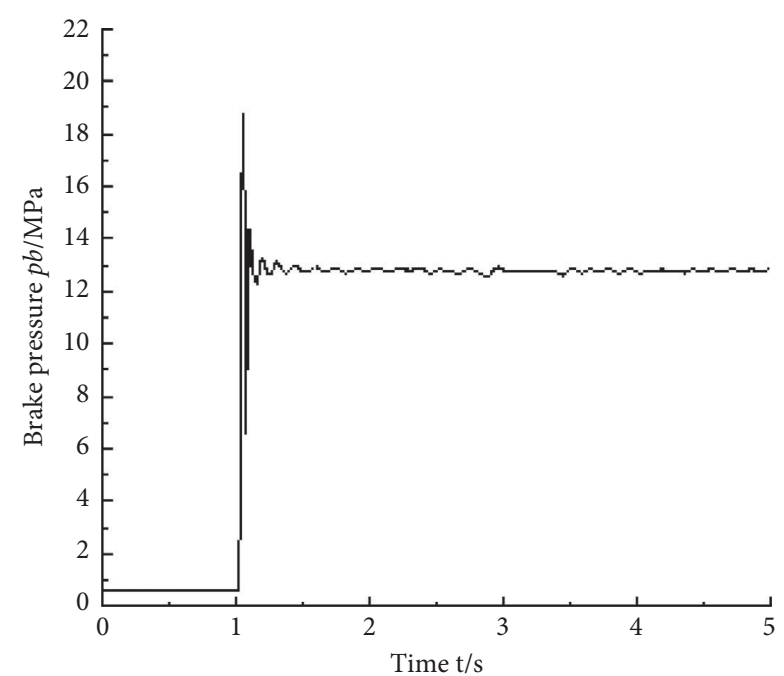

(d)

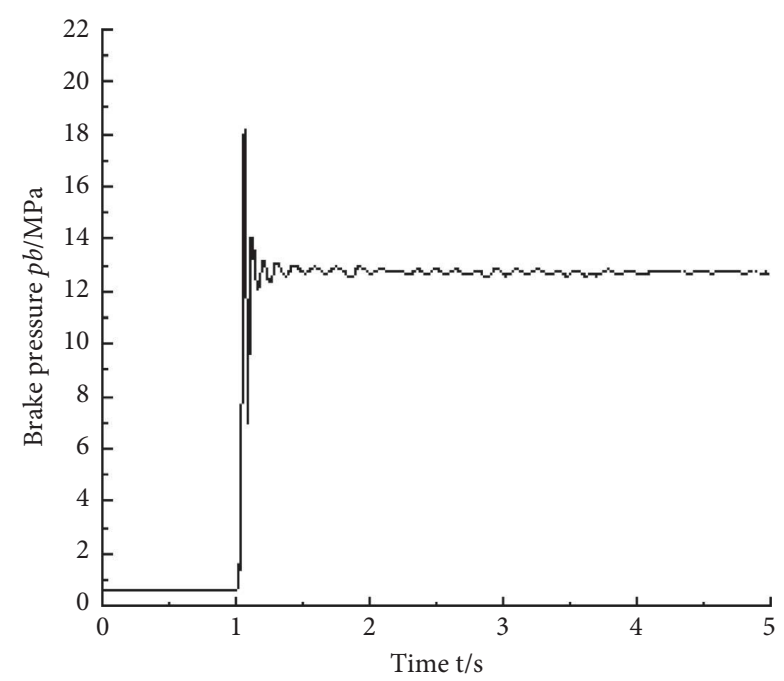

(f)

Figure 21: Pressure output of two-stage brake pressure servo valve-controlled cylinder system at 21 MPa oil supply pressure. (a) 1-valve opening. (b) 2-valve opening. (c) 3-valve opening. (d) 4-valve opening. (e) 5-valve opening. (f) 6-valve opening. 
and the influence of the experimental environment such as temperature, noise, leakage, and other factors.

\section{Conclusion}

Aiming at the phenomenon of constant amplitude periodic oscillation of brake pressure in the debugging process of the aircraft brake system, this paper focuses on the pressure servo valve in the aircraft brake system; the working principle and feedback stage function of the three-stage brake pressure servo valve in the system are analyzed. The feedback stage of the pressure servo valve can improve the stability and control accuracy of the recovery pressure of the system and restrain the positive feedback effect of oil return. In view of the adverse influence of the positive feedback effect of oil return, starting with the structure of the servo valve itself, the design and principle analysis of a new two-stage brake pressure servo valve is carried out, and its dynamic model is built for simulation analysis. The simulation model of a multivalve parallel brake servo control system is built for simulation analysis, and the influence of opening different numbers of two-stage brake pressure servo valves on the system is compared and analyzed. Through the simulation analysis, under the condition of multivalve parallel operation, the two-stage brake pressure servo valve cylinder control system can still maintain fast and stable brake pressure output. A prototype of a new type of brake pressure servo valve is designed, the experimental platform of brake pressure servo valve cylinder control system is set up, and the brake pressure oscillation of the new two-stage pressure servo valve is compared with that of the three-stage brake pressure servo valve. The brake pressure output of the system is tested by opening different numbers of two-stage brake pressure servo valves. The experimental results show that the new two-stage pressure servo valve can effectively restrain the vibration of the multivalve parallel brake system. The two-stage pressure servo valve has been successfully applied to the practical aircraft brake system.

6.1. Further Research in the Future. When the plane landed, the runway pavement condition, the influence of the elevation plane landing, each wheel under the impact, and runway friction effect that has an obvious difference, the time under the influence of flight control system control, multiple parallel brake valve systems of each brake pressure servo valve control cylinder system in the load that is significantly different, the effect of the random load and load caused by the coupling effect, and the influence on multiwheel brake system still need to be further studied.

\section{Data Availability}

The data used to support the findings of this study are included within the article.

\section{Conflicts of Interest}

The authors declare that they have no conflicts of interest.

\section{Acknowledgments}

This research is funded by National Excellent Young Scientists Fund (Grant No. 52122503), National Natural Science Foundation of China (Grant No. 51975506) and "Youth Top Talent Program Project" of Hebei Province University Science and Technology Research Project (Grant No. BJ2020016).

\section{References}

[1] W. Zhang, T. Yue, and L.-X. Wang, "Research on lateraldirectional dynamic characteristics and control for large envelope flight of modular aircraft," in Proceedings of the $3 \mathrm{rd}$ Annual International Conference on Mechanics and Mechanical Engineering (MME 2016), Chengdu, China, December 2016.

[2] Y. Che, J. Xu, K. Shi, H. Liu, W. Chen, and D. Yu, "Stability analysis of aircraft power systems based on a unified large signal model," Energies, vol. 10, no. 11, Article ID 1739, 2017.

[3] K. F. Vajargah, "Evaluating the parametric, semi-parametric and nonparametric models for reliability in aircraft braking system," Mathematical Sciences, vol. 15, no. 3, pp. 259-267, 2020.

[4] M. Q. Chen, W. S. Liu, Y. Z. Ma, J. Wang, F. R. Xu, and Y. J. Wang, "Mixed slip-deceleration PID control of aircraft wheel braking system," IFAC-PapersOnLine, vol. 51, no. 4, pp. 160-165, 2018.

[5] Y. Chu, Z. Yuan, and W. Chang, "Research on the dynamic erosion wear characteristics of a nozzle flapper pressure servo valve used in aircraft brake system," Mathematical Problems in Engineering, vol. 2020, Article ID 3136412, 13 pages, 2020.

[6] Z. X. Jiao, D. Sun, Y. X. Sun, Y. X. Shang, X. C. Liu, and S. Wu, "A high efficiency aircraft anti-skid brake control with runway identification," Aerospace Science and Technology, vol. 91, 2019.

[7] X. H. Hai, S. J. Zhang, and X. D. Xu, "Civil aircraft landing gear brake system development and evaluation using model based system engineeringt," in Proceedings of the 36th China Control Conference, Dalian, China, July 2017.

[8] M. Viscardi, M. Arena, P. Cerreta, P. Iaccarino, and S. I. Imparato, "Manufacturing and validation of a novel composite component for aircraft main landing gear Bay," Journal of Materials Engineering and Performance, vol. 28, no. 6, pp. 3292-3300, 2019.

[9] J. Lin, J. Pulido, and M. Asplund, "Reliability analysis for preventive maintenance based on classical and Bayesian semiparametric degradation approaches using locomotive wheelsets as a case study," Reliability Engineering \& System Safety, vol. 134, pp. 143-156, 2015.

[10] M. M. Alamelu, "Vibration based condition monitoring of a brake system using Statistical features with logit boost and simple logistic algorithm," International Journal of Performability Engineering, vol. 14, no. 1, pp. 1-8, 2018.

[11] J. Kang, Z. Yuan, and M. Tariq Sadiq, "Numerical simulation and experimental research on flow force and pressure stability in a nozzle-flapper servo valve," Processes, vol. 8, no. 11, Article ID 1404, 2020.

[12] Z. Jiao, H. Zhang, Y. Shang, X. Liu, and S. Wu, "A power-bywire aircraft brake system based on high-speed on-off valves," Aerospace Science and Technology, vol. 106, Article ID 106177, 2020.

[13] M. A. Aravind and N. S. Dinesh, "Rajanna application of EMPC for precise position control of DC-motor system with 
backlash," Control Engineering Practice, vol. 100, Article ID 104422, 2020.

[14] J.-J. Sinou, O. Dereure, G.-B. Mazet, F. Thouverez, and L. Jezequel, "Friction-induced vibration for an aircraft brake system-Part 1: experimental approach and stability analysis," International Journal of Mechanical Sciences, vol. 48, no. 5, pp. 536-554, 2006.

[15] Q. Yin, X. Wei, H. Nie, and J. Deng, "Study on modal characteristics and vibration reduction of an aircraft rotorstator brake-induced squeal system," Acta Mechanica Sinica, vol. 36, no. 6, pp. 1350-1359, 2020.

[16] L. Wu, L. Zhang, K. S. Chen, and C. C. Zhan, "Effect of key structures and parameters on dynamic characteristics of three-stage jet-pipe servo valve," in Proceedings of the IOP Conference Series: Materials Science and Engineering, Sanya, China, 2019.

[17] Q. F. Zhang, Y. Liang, Z. H. Duan, and Z. X. Jiao, "High torque density torque motor with hybrid magnetization pole arrays for jet pipe servo valve," IEEE Transactions on Industrial Electronics, vol. 67, no. 3, pp. 2133-2142, 2019.

[18] S. Li, N. Z. Aung, S. Zhang, J. Cao, and X. Xue, "Experimental and numerical investigation of cavitation phenomenon in flapper-nozzle pilot stage of an electrohydraulic servo-valve," Computers \& Fluids, vol. 88, no. 15, pp. 590-598, 2013.

[19] Y. Wang and Y. Yin, "Performance reliability of jet pipe servo valve under random vibration environment," Mechatronics, vol. 64, Article ID 102286, 2019.

[20] A. Tetsuya, D. Shujiro, K. Wataru, H. Shota, and K. Keiichiro, "Improvement of dynamic characteristics of low-cost servo valve using buckled tubes and rc servo motor," in Proceedings of the international Conference on Robotics \& Automation Sciences, pp. 26-29, Hong Kong, China, August 2017.

[21] G. L. Wang, Y. X. Zhang, and X. D. ,Pan, "Research on a precise grinding device for servo valve spool," in Proceedings of the 15th International Conference on Ubiquitous Robots (UR), Honolulu, USA, June 2018.

[22] X. B. Lv, V. Lomakin, and S. J. Li, "Performance and flow field analysis of flapper deflection servo valve," in Proceedings of the Global Fluid Power Society PhD Symposium (GFPS), pp. 1820, Samara, Russia, July 2018.

[23] L. Zhang, Z. Huang, C. Fu, Y. Xu, Y. Wang, and X. Kong, "Design and verification of two-stage brake pressure servo valve for aircraft brake system," Processes, vol. 9, no. 6, p. 979, 2021. 